\title{
Chemical and radiative transfer modeling of propylene oxide
}

\author{
Ankan Das, Prasanta Gorai, and Sandip K. Chakrabarti
}

\author{
Indian Centre for Space Physics, 43 Chalantika, Garia Station Road, Kolkata 700084, India \\ e-mail: ankan@csp.res.in
}

Received 19 December 2018 / Accepted 10 June 2019

\begin{abstract}
Context. The recent identification of the first complex chiral molecule, propylene oxide (PrO), in space opens up a new window to further study the origin of homochirality on the Earth. There are some recent studies to explain the formation of PrO however additional studies on the formation of this species are needed for better understanding.

Aims. We seek to prepare a complete reaction network to study the formation of propylene oxide in the astrophysically relevant conditions. Based on our results, a detailed radiative transfer modeling has been carried out to propose some more transitions that would potentially be targeted in the millimeter wave domain.

Methods. A gas-grain chemical network was used to explain the observed abundance of PrO in a cold shell surrounding the high-mass star-forming region of Sgr B2. Quantum chemical calculations were employed to study various reaction parameters and to compute multiple vibrational frequencies of PrO.

Results. To model the formation of PrO in the observed region, we considered a dark cloud model. Additionally, we used a model to check the feasibility of forming PrO in the hot core region. Some potential transitions in the millimeter wave domain are predicted that could be useful for the future astronomical detection. We used radiative transfer modeling to extract the physical condition that might be useful to know the properties of the source in detail. Moreover, we provided vibrational transitions of PrO, which could be very useful for the future detection of PrO by the upcoming James Webb Space Telescope.
\end{abstract}

Key words. astrochemistry - methods: numerical - ISM: abundances - ISM: molecules - line: identification

\section{Introduction}

The discovery of a large number of complex interstellar species have significantly improved our understanding of the chemical processes involved in the interstellar medium (ISM). It is speculated that the building blocks of life (biomolecules) were formed in the ISM and were delivered by the comets to the Earth in the later stages (Chyba et al. 1990; Raymond et al. 2004; Hartogh et al. 2011). These life-making primordial organic compounds may also have been formed in the pre-solar nebula rather than on the early Earth (Bailey et al. 1998; Chakrabarti \& Chakrabarti 2000a,b; Hunt-Cunningham \& Jones 2004; Holtom et al. 2005; Buse et al. 2006; Herbst \& van Dishoeck 2009). The prospect of extraterrestrial origin of biomolecules is a fascinating topic since many biomolecules are chiral. Synthesis and detection of prebiotic molecules in the ISM have been studied and discussed by various authors (Cunningham et al. 2007; Das et al. 2008a; Gupta et al. 2011; Majumdar et al. 2012; Garrod \& Herbst 2006; Nuevo et al. 2014; Chakrabarti et al. 2015). In between the living organisms on the Earth, amino acids and sugars are chiral. Interestingly, most of the amino acids of terrestrial proteins and sugars found on the Earth are homochiral; amino acids are left-handed whereas sugars are right-handed. When and how this homochirality developed on the Earth is a matter of debate (Cohen et al. 1995). Various biomolecules were identified in the Murchison meteorite. Interestingly, an excess amount of L-amino acids were identified (Engel \& Nagy 1982; Engel \& Macko 1997), which also suggest an extraterrestrial source for molecular asymmetry in the solar system. Thus, observation of more chiral species along with their enantiomeric excess in space could be very useful for the better understanding of the origin of homochirality. But unfortunately, with the present observational facility, it is very difficult to define the enantiomeric excess of an interstellar species.

Cunningham et al. (2007) attempted to observe $\mathrm{PrO}$ in the Orion KL and Sgr B2(LMH) using the Mopra Telescope. Based on their observational results, they predicted an upper limit on the column density $\left(\sim 6.7 \times 10^{14} \mathrm{~cm}^{-2}\right)$ of PrO in the Sgr B2 $(\mathrm{LMH})$ and predicted an excitation temperature of $200 \mathrm{~K}$ with a compact source size of $5^{\prime \prime}$. Recently, McGuire et al. (2016) attempted to search for the existence of a complex chiral species in space. They targeted star-forming regions such as Sgr B2 with Parkes Observatory and Green Bank Telescope (GBT) and successfully identified the first complex chiral molecule (PrO) in space. They were unable to determine the enantiomeric excess of PrO because of the lack of high precision and full polarization state measurement. McGuire et al. (2016) identified three transitions of $\mathrm{PrO}$ in absorption that correspond to the excitation temperature of $\sim 5 \mathrm{~K}$ and column density $\sim 1 \times 10^{13} \mathrm{~cm}^{-2}$.

PrO has a significant proton affinity (Hunter \& Lias 1998) and should be converted into protonated form through some ionneutral (IN) reactions. Panels a, b, and c of Fig. 1 depict the structure of $\mathrm{PrO}$ and its two protonated forms, respectively. Swalen \& Hershbach (1957) and Hershbach \& Swalen (1958) discussed the internal barrier of $\mathrm{PrO}$ and its various rotational transitions in the ground and torsionally excited states. Later, Creswell \& Schwendeman (1977) calculated the centrifugal distortional constants and structural parameters of PrO. The absorption spectrum of PrO was studied by various authors (Polavarapu et al. 1985; Lowe et al. 1986; Gontrani et al. 2014). Recently, the IR spectrum of solid PrO was experimentally obtained by Hudson et al. (2017). These authors also proposed that the reaction between 

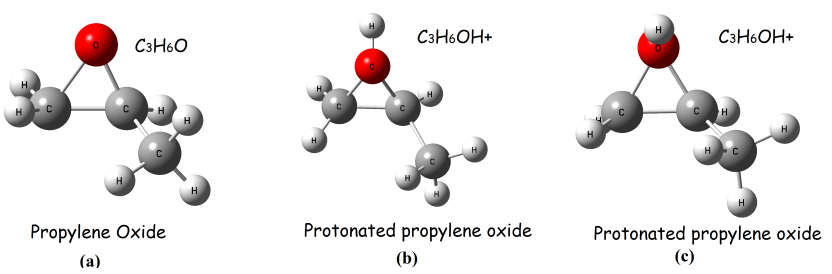

Fig. 1. Structure of propylene oxide and two of its protonated forms.

$\mathrm{O}$ atom and $\mathrm{C}_{3} \mathrm{H}_{6}$ may lead to the formation of $\mathrm{PrO}$ and its four other isomers. We considered these pathways in our model to study the formation of $\mathrm{PrO}$ and its isomers.

A large number of observational and theoretical studies reveal that complex organic molecules (COMs) begin to form in the cold region of the dense molecular cloud. Cosmic dust particles act as a reservoir for molecules and also as a catalyst for reactions, which lead to the formation of COMs in molecular clouds (Öberg et al. 2009; Bacmann et al. 2012; Das et al. 2016). In low temperature and moderately high-density regions, gas phase exothermic reactions (such as IN reactions) are more feasible because they do not possess any activation barrier (Agúndez \& Wakelam 2013). At the same time, various irradiation-triggered solid-phase reactions also contribute to the formation of various complex interstellar species. In the low temperature, nonthermal desorption mechanism plays an efficient means to transport the surface species into the gas phase upon its formation. In this process, all the surface reactions that are exothermic and resulting in a single product can break the surface-molecule bond with some fraction and transfer the surface species to the gas phase (Garrod et al. 2007). Nonthermal reactions on the grain surface also play a crucial role in governing the abundances of the surface species where the diffusion of atom (ground state) or radical diffusion chemistry is inefficient. Oxygen $\left({ }^{1} \mathrm{D}\right)$ insertion reaction mentioned in Bergner et al. (2017) and Bergantini et al. (2018) can be characterized as nonthermal reactions. These excited oxygens or suprathermal oxygens $\left({ }^{1} \mathrm{D}\right)$ are mainly produced by the effects of secondary electrons generated in the path of cosmic rays when it is in contact with the grain mantle. The main sources of these oxygens are the various oxygen rich species such as $\mathrm{CO}_{2}, \mathrm{H}_{2} \mathrm{O}$, and $\mathrm{CO}$.

Occhiogrosso et al. (2012) carried out theoretical modeling for the formation of ethylene oxide (EO) in space. These authors were able to reproduce the observed abundance of EO successfully. Additionally, they considered the reaction between $\mathrm{C}_{3} \mathrm{H}_{6}$ and $\mathrm{O}$ on the surface to include the formation of PrO. However, they did not include a complete reaction network for the creation and destruction of $\mathrm{PrO}$ and its associated species. More importantly, they did not consider the formation of $\mathrm{C}_{3} \mathrm{H}_{6}$ on the grain surface. Recently Hickson et al. (2016) provided some pathways for the formation of $\mathrm{C}_{3} \mathrm{H}_{6}$ on the grain surface that eventually can produce $\mathrm{PrO}$.

In this paper, we study the synthesis of PrO along with two of its structural isomers, namely, propanal and acetone in star-forming conditions. We carried out the radiative transfer models to identify the most active transition of $\mathrm{PrO}$ in the millimeter $(\mathrm{mm})$ wave regions. Absorption features of PrO and integral absorption coefficients obtained with high-level quantum chemical methods could be handy for its future detection by the high-resolution Stratospheric Observatory for Infrared Astronomy (SOFIA) and the most-awaited James Webb Space Telescope (JWST). The remainder of this paper is as follows: Sect. 2 describes the reaction pathways considered in our modeling. In Sect. 3, we discuss chemical modeling. In Sect. 4,
Table 1. Surface reactions for propylene and propylene oxide synthesis.

\begin{tabular}{|c|c|c|}
\hline $\begin{array}{l}\text { Reaction } \\
\text { number (type) }\end{array}$ & Reaction & $\begin{array}{l}E_{\mathrm{a}} \text { in } \\
\text { Kelvin }\end{array}$ \\
\hline $\mathrm{R} 1(\mathrm{NR})^{(a)}$ & $\begin{array}{c}\mathrm{H}+\mathrm{C}_{3} \rightarrow 1-\mathrm{C}_{3} \mathrm{H} \\
\rightarrow \mathrm{c}-\mathrm{C}_{3} \mathrm{H}\end{array}$ & $\begin{array}{l}0 \\
0\end{array}$ \\
\hline $\mathrm{R} 2(\mathrm{RR})^{(a)}$ & $\begin{array}{c}\mathrm{H}+1-\mathrm{C}_{3} \mathrm{H} \rightarrow 1-\mathrm{C}_{3} \mathrm{H}_{2} \\
\rightarrow \mathrm{c}-\mathrm{C}_{3} \mathrm{H}_{2}\end{array}$ & $\begin{array}{l}0 \\
0\end{array}$ \\
\hline $\mathrm{R} 3(\mathrm{RR})^{(a)}$ & $\begin{array}{c}\mathrm{H}+\mathrm{c}-\mathrm{C}_{3} \mathrm{H} \rightarrow \mathrm{c}-\mathrm{C}_{3} \mathrm{H}_{2} \\
\rightarrow 1-\mathrm{C}_{3} \mathrm{H}_{2}\end{array}$ & $\begin{array}{l}0 \\
0\end{array}$ \\
\hline $\mathrm{R} 4(\mathrm{NR})^{(a)}$ & $\mathrm{H}+\mathrm{c}, \mathrm{l}-\mathrm{C}_{3} \mathrm{H}_{2} \rightarrow \mathrm{C}_{3} \mathrm{H}_{3}\left(\mathrm{CH}_{2} \mathrm{CCH}\right)$ & 0 \\
\hline $\mathrm{R} 5(\mathrm{RR})^{(a)}$ & $\begin{aligned} \mathrm{H}+ & \mathrm{C}_{3} \mathrm{H}_{3} \rightarrow \mathrm{CH}_{3} \mathrm{CCH} \\
& \rightarrow \mathrm{CH}_{2} \mathrm{CCH}_{2}\end{aligned}$ & $\begin{array}{l}0 \\
0\end{array}$ \\
\hline $\mathrm{R} 6(\mathrm{NR})^{(a)}$ & $\mathrm{H}+\mathrm{CH}_{3} \mathrm{CCH} \rightarrow \mathrm{C}_{3} \mathrm{H}_{5}$ & 2013 \\
\hline $\mathrm{R} 7(\mathrm{NR})^{(b)}$ & $\mathrm{H}+\mathrm{CH}_{2} \mathrm{CCH}_{2} \rightarrow \mathrm{C}_{3} \mathrm{H}_{5}$ & 0 \\
\hline $\mathrm{R} 8(\mathrm{RR})^{(a)}$ & $\mathrm{H}+\mathrm{C}_{3} \mathrm{H}_{5} \rightarrow \mathrm{C}_{3} \mathrm{H}_{6}$ & 0 \\
\hline $\mathrm{R} 9(\mathrm{NR})^{(a)}$ & $\mathrm{H}+\mathrm{C}_{3} \mathrm{H}_{6} \rightarrow \mathrm{C}_{3} \mathrm{H}_{7}$ & 1600 \\
\hline $\mathrm{R} 10(\mathrm{RR})^{(a)}$ & $\mathrm{H}+\mathrm{C}_{3} \mathrm{H}_{7} \rightarrow \mathrm{C}_{3} \mathrm{H}_{8}$ & 0 \\
\hline $\mathrm{R} 11(\mathrm{NR})^{(a)}$ & $\mathrm{H}+\mathrm{C}_{3} \mathrm{H}_{8} \rightarrow \mathrm{C}_{3} \mathrm{H}_{7}+\mathrm{H}_{2}$ & 4000 \\
\hline $\mathrm{R} 12(\mathrm{NR})$ & $\mathrm{O}\left({ }^{3} \mathrm{P}\right)+\mathrm{C}_{3} \mathrm{H}_{6} \rightarrow \mathrm{CH}_{3} \mathrm{COCH}_{3}$ & $28.6^{(c)}$ \\
\hline R13(NR) & $\mathrm{O}\left({ }^{3} \mathrm{P}\right)+\mathrm{C}_{3} \mathrm{H}_{6} \rightarrow \mathrm{CH}_{3} \mathrm{CH}_{2} \mathrm{CHO}$ & $30.6^{(c)}$ \\
\hline R14(NR) & $\mathrm{O}\left({ }^{3} \mathrm{P}\right)+\mathrm{C}_{3} \mathrm{H}_{6} \rightarrow 1-$ methyl vinyl alcohol & $32.8^{(c)}$ \\
\hline R15(NR) & $\mathrm{O}\left({ }^{3} \mathrm{P}\right)+\mathrm{C}_{3} \mathrm{H}_{6} \rightarrow 2-$ methyl vinyl alcohol & $33.8^{(c)}$ \\
\hline R16(NR) & $\mathrm{O}\left({ }^{3} \mathrm{P}\right)+\mathrm{C}_{3} \mathrm{H}_{6} \rightarrow \mathrm{PrO}$ & $40^{(d)}$ \\
\hline R17(NR) & $\mathrm{O}\left({ }^{1} \mathrm{D}\right) / \mathrm{O}^{*}+\mathrm{C}_{3} \mathrm{H}_{6} \rightarrow \mathrm{PrO}$ & $(e)$ \\
\hline R18(NR) & $\mathrm{CH}+\mathrm{C}_{2} \mathrm{H}_{6} \rightarrow \mathrm{C}_{3} \mathrm{H}_{6}+\mathrm{H}$ & Branching ratio $0.25^{(e)}$ \\
\hline R19(NR) & $\mathrm{CH}+\mathrm{C}_{2} \mathrm{H}_{6} \rightarrow \mathrm{C}_{2} \mathrm{H}_{4}+\mathrm{CH}_{3}$ & Branching ratio $0.75^{(e)}$ \\
\hline
\end{tabular}

References. ${ }^{(a)}$ Hickson et al. (2016), ${ }^{(b)}$ http://kinetics.nist. gov/kinetics/, ${ }^{(c)}$ this work, ${ }^{(d)}$ Ward \& Price $(2011),{ }^{(e)}$ Bergantini et al. (2018).

Table 2. Kinetics of the reaction between $\mathrm{C}_{3} \mathrm{H}_{6}$ and $\mathrm{O}$.

\begin{tabular}{|c|c|c|c|}
\hline \multirow{2}{*}{$\begin{array}{l}\text { Reaction } \\
\text { number } \\
\text { (type) }\end{array}$} & \multirow[t]{2}{*}{ Reaction } & \multicolumn{2}{|c|}{ Enthalpy of the reaction $\left(\mathrm{Kcal} \mathrm{mol}^{-1}\right)$} \\
\hline & & $\begin{array}{l}\text { Gas phase } \\
\text { (scaled } E_{a} \text { in } \mathrm{K} \text { ) } \\
(\text { rate @ } 30 \mathrm{~K} \\
\text { in } \mathrm{cm}^{3} \mathrm{~s}^{-1} \text { ) }\end{array}$ & $\begin{array}{l}\text { Ice phase } \\
\text { (scaled } E_{a} \text { in } \mathrm{K} \text { ) } \\
(\text { rate @ } 25 \mathrm{~K} \text { in } \\
\mathrm{s}^{-1} \text { ) }\end{array}$ \\
\hline $\mathrm{R} 12(\mathrm{NR})$ & $\begin{array}{l}\mathrm{O}\left({ }^{3} \mathrm{P}\right)+\mathrm{C}_{3} \mathrm{H}_{6} \\
\rightarrow \mathrm{CH}_{3} \mathrm{COCH}_{3}\end{array}$ & $\begin{array}{l}-112.87(-17.4) \\
\left(9.7 \times 10^{-14}\right)\end{array}$ & $\begin{array}{l}-116.17(28.6) \\
\left(2.0 \times 10^{-12}\right)\end{array}$ \\
\hline R13(NR) & $\begin{array}{l}\mathrm{O}\left({ }^{3} \mathrm{P}\right)+\mathrm{C}_{3} \mathrm{H}_{6} \\
\rightarrow \mathrm{CH}_{3} \mathrm{CH}_{2} \mathrm{CHO}\end{array}$ & $\begin{array}{l}-105.88(-16.3) \\
\left(9.4 \times 10^{-14}\right)\end{array}$ & $\begin{array}{l}-108.51(30.6) \\
\left(1.6 \times 10^{-12}\right)\end{array}$ \\
\hline R14(NR) & $\begin{array}{l}\mathrm{O}\left({ }^{3} \mathrm{P}\right)+\mathrm{C}_{3} \mathrm{H}_{6} \\
\rightarrow 1-\mathrm{MVA}\end{array}$ & $\begin{array}{l}-98.30(-15.2) \\
\left(9.0 \times 10^{-14}\right)\end{array}$ & $\begin{array}{l}-101.25(32.8) \\
\left(1.2 \times 10^{-12}\right)\end{array}$ \\
\hline $\mathrm{R} 15(\mathrm{NR})$ & $\begin{array}{l}\mathrm{O}\left({ }^{3} \mathrm{P}\right)+\mathrm{C}_{3} \mathrm{H}_{6} \\
\rightarrow 2-\mathrm{MVA}\end{array}$ & $\begin{array}{l}-95.64(-14.7) \\
\left(8.9 \times 10^{-14}\right)\end{array}$ & $\begin{array}{l}-98.05(33.8) \\
\left(1.1 \times 10^{-12}\right)\end{array}$ \\
\hline R16(NR) & $\begin{array}{l}\mathrm{O}\left({ }^{3} \mathrm{P}\right)+\mathrm{C}_{3} \mathrm{H}_{6} \\
\rightarrow \mathrm{PrO}\end{array}$ & $\begin{array}{l}-81.09(-12.5) \\
\left(8.3 \times 10^{-14}\right)\end{array}$ & $\begin{array}{l}-82.92(40.0) \\
\left(5.2 \times 10^{-13}\right)\end{array}$ \\
\hline
\end{tabular}

vibrational spectroscopy is presented. Radiative transfer modeling is discussed in Sect. 5, and finally, in Sect. 6 we draw our conclusions.

\section{Reaction pathways}

\subsection{Methodology}

To study the formation and destruction reactions of propylene oxide and associated species, we considered both gas phase and grain surface reactions. To study the reaction pathways, we employed quantum chemical methods. We carried out quantum chemical calculations to find out the reaction enthalpies of these gas/ice phase reactions. In Table 1, we summarize all the surface reactions considered for the formation of propylene and propyline oxide. In Table 2, we provide the enthalpy of reactions between $\mathrm{C}_{3} \mathrm{H}_{6}$ and $\mathrm{O}\left({ }^{3} \mathrm{P}\right)$ for five (R12-R16) product channels. The Gaussian 09 program was used (Frisch et al. 2015) for such calculations. In this work, we used the density functional theorem (DFT) with 6-311G basis set with the inclusion of diffuse $(++)$ along with polarization functions $(\mathrm{d}, \mathrm{p})$ and B3LYP 
functional (Becke 1988; Lee et al. 1988). We used the polarizable continuum model using the integral equation formalism variant with the default self-consistent reaction field method (SCRF) to model the solvation-effect for the computation of enthalpy of the ice phase reactions.

\subsection{Formation pathways}

Marcelino et al. (2007) discovered propylene $\left(\mathrm{C}_{3} \mathrm{H}_{6}\right)$ toward the TMC -1 by using the IRAM $30 \mathrm{~m}$ radio telescope. These authors estimated the column density of propylene $\sim 4 \times 10^{13} \mathrm{~cm}^{-2}$. Herbst et al. (2010) studied the formation of gas phase propylene in the cold interstellar cloud. They proposed that propylene could mainly be formed by the dissociative recombination (DR) of its precursor ion, $\mathrm{H}_{3} \mathrm{CCHCH}_{3}^{+}$via $\mathrm{C}_{3} \mathrm{H}_{7}^{+}+\mathrm{e}^{-} \rightarrow \mathrm{C}_{3} \mathrm{H}_{6}+\mathrm{H}$. For the formation of $\mathrm{C}_{3} \mathrm{H}_{7}^{+}$, the following reactions were included in the UMIST 2012 (McElroy et al. 2013) network:

$$
\begin{aligned}
& \mathrm{C}_{3} \mathrm{H}_{3}^{+}+\mathrm{H}_{2} \rightarrow \mathrm{C}_{3} \mathrm{H}_{5}^{+}, \\
& \mathrm{C}_{3} \mathrm{H}_{5}^{+}+\mathrm{H}_{2} \rightarrow \mathrm{C}_{3} \mathrm{H}_{7}^{+} .
\end{aligned}
$$

But a recent study by Lin et al. (2013) found that above two reactions contain some activation barrier (25.5 and $24.7 \mathrm{~kJ} \mathrm{~mol}^{-1}$, respectively). In the low-temperature regime, it is problematic to overcome such a high barrier in the gas phase and thus the formation of gas phase $\mathrm{C}_{3} \mathrm{H}_{7}^{+}$is inadequate by these routes; this suggests considering some alternative reaction pathways to enable the formation of $\mathrm{C}_{3} \mathrm{H}_{6}$ rather than by the electron recombination reaction as proposed by Herbst et al. (2010). Recently, Hickson et al. (2016) proposed some pathways for the formation of $\mathrm{C}_{3} \mathrm{H}_{6}$ in the ice phase. In this work, we also considered their pathways for the formation of this species. In Table 1, we list the formation and destruction pathways of $\mathrm{C}_{3} \mathrm{H}_{6}$ found in the literature and calculated in this work. Though we considered the formation of $\mathrm{C}_{3}$ on the grain surface, around the low temperature, its formation on the grain surface is not adequate owing to the higher binding energy ( $4000 \mathrm{~K}$ from the KIDA database) of the $\mathrm{C}$ atom. $\mathrm{C}_{3}$ is efficiently forming on the gas phase and thus the formation of $\mathrm{C}_{3} \mathrm{H}_{6}$ begins after the accretion of gas phase $\mathrm{C}_{3}$ on the grain surface. Sequential hydrogenation reactions (R1-R8 of Table 1) in the ice phase then leads to the formation of $\mathrm{C}_{3} \mathrm{H}_{6}$. Most of these hydrogenation reactions are barrierless (only reaction R6 has some barrier), so these pathways are very efficient for the formation of $\mathrm{C}_{3} \mathrm{H}_{6}$ in ice phase. Recently, Bergantini et al. (2018) used the reaction between $\mathrm{CH}$ and $\mathrm{C}_{2} \mathrm{H}_{6}$ for the formation of propylene with a branching fraction of 0.25 (R18). We also considered reaction numbers R18 and R19 (0.75 branching fraction) of Table 1 in our calculations. A high abundance of ice phase species may be reflected in the gas phase by various efficient desorption mechanisms such as thermal, nonthermal, and cosmic-ray-induced desorption.

The gas phase reaction between oxygen atom $\mathrm{O}\left({ }^{3} \mathrm{P}\right)$ and propylene $\left(\mathrm{C}_{3} \mathrm{H}_{6}\right)$ has been well studied by several authors (Stuhl \& Niki 1971; Atkinson \& Cvetanov 1972; Atkinson \& Pitts 1974; Knya et al. 1992). The branching ratios of the reaction between $\mathrm{C}_{3} \mathrm{H}_{6}$ and $\mathrm{O}$ atom were studied by DeBoer \& Dodd (2007). They showed that the propylene and oxygen atom could form a stable biradical $\left(\mathrm{CH}_{3} \mathrm{CHCH}_{2} \mathrm{O}\right)$ having an activation barrier of $\sim 7.5 \mathrm{~kJ} \mathrm{~mol}^{-1}$. Dissociation of this biradical follows various pathways with both singlet and triplet potential energy surfaces. Isomerization of $\mathrm{PrO}$ can produce (a) acetone, (b) propanal (c) methyl vinyl alcohol, and (d) ally alcohol. However, all these have to overcome very high activation barriers
(Dubnikova \& Lifshitz 2000), which is not possible at our desired environment.

Ward \& Price (2011) described the production of EO and PrO on interstellar dust (graphite surface). They found an activation barrier of about $40 \mathrm{~K}$ for the formation of $\mathrm{PrO}$ by the reaction between $\mathrm{C}_{3} \mathrm{H}_{6}$ and $\mathrm{O}\left({ }^{3} \mathrm{P}\right)$. Hudson et al. (2017) proposed that the reaction between $\mathrm{O}\left({ }^{3} \mathrm{P}\right)$ atom and $\mathrm{C}_{3} \mathrm{H}_{6}$ can produce any of the following five species, namely, (i) propylene oxide $\left(\mathrm{C}_{3} \mathrm{H}_{6} \mathrm{O}\right)$, (ii) propanol $\left(\mathrm{CH}_{3} \mathrm{CH}_{2} \mathrm{CHO}\right)$, (iii) 1-methyl vinyl alcohol $\left(\mathrm{CH}_{3} \mathrm{COHCH} 2\right)$, (iv) acetone $\left(\mathrm{CH}_{3} \mathrm{COCH}_{3}\right)$, and (v) 2-methyl vinyl alcohol $\left(\mathrm{CH}_{3} \mathrm{CHCHOH}\right)$. We carried out quantum chemical calculations to find out the reaction enthalpies of these gas/ice phase reactions. In Table 2, we show the enthalpy of reactions between $\mathrm{C}_{3} \mathrm{H}_{6}$ and $\mathrm{O}\left({ }^{3} \mathrm{P}\right)$ for these five (R12-R16) product channels. Table 2 depicts that in between the five product channels (R12-R16), the production of acetone is comparatively most favorable and the production of $\mathrm{PrO}$ is least favorable. In Table 1, reactions R12-R16 are arranged according to their exothermicity values obtained from our calculated values in Table 2. Ward \& Price (2011) found an activation barrier of about $40 \mathrm{~K}$ for the formation of ice phase PrO. We considered the activation barrier of the other product channels using a scaling factor based on their exothermicity values obtained from the ice phase reactions of Table 2 . The ice phase rate coefficients of these reactions (R12-R16) were calculated by the method described in Hasegawa et al. (1992), which is based on thermal diffusion. For the binding energy of $\mathrm{O}$, we used $1660 \mathrm{~K}$ (He et al. 2015) and for $\mathrm{C}_{3} \mathrm{H}_{6}$ we used $2580 \mathrm{~K}$ (Ward \& Price 2011), respectively. For the other species, we considered the most updated set of energy barriers available in KIDA database. Calculated ice phase rates for these five product channels are shown in the last column of Table 2 for $\left(T_{\text {ice }}=25 \mathrm{~K}\right)$.

Recently Leonori et al. (2015) computed the rate constant for the formation of gas phase PrO at high temperature for the addition and abstraction reactions interpolated between $300-2000 \mathrm{~K}$. According to their results, formation of $\mathrm{PrO}$ by the addition of $\mathrm{C}_{3} \mathrm{H}_{6}$ and $\mathrm{O}\left({ }^{3} \mathrm{P}\right)$ can be approximated by the following Arrhenius expression:

$K=\alpha T^{\beta} \exp \left(-E_{\mathrm{a}} / T\right) \mathrm{cm}^{3}$ molecules ${ }^{-1} \mathrm{~s}^{-1}$,

where $\alpha=4.52 \times 10^{-16}, \beta=1.406$ and $E_{\mathrm{a}}$, the activation barrier is $-12.5 \mathrm{~K}$. We assumed that this reaction is also feasible around the low temperature as well. Using the above relation, at $30 \mathrm{~K}$, we have a rate of $8.3 \times 10^{-14} \mathrm{~cm}^{3} \mathrm{~s}^{-1}$ for the formation of gas phase PrO (R16 of Table 2). Since the activation barrier for the other four products resulting from the gas phase reaction between $\mathrm{C}_{3} \mathrm{H}_{6}$ and $\mathrm{O}$ (R12-R15 of Table 2) are yet to be known, we used their gas phase exothermicity values pointed out in Table 2 to scale the activation barrier $\left(E_{\mathrm{a}}\right)$. Thus, for these four product channels, we have kept $\alpha$ and $\beta$ same as the gas phase reaction number R16 of Table 2 and have scaled $E_{\mathrm{a}}$ according to their exothermicity values.

Dickens et al. (1997) proposed the following gas phase formation pathways of $\mathrm{EO}$ :

$\mathrm{CH}_{3}^{+}+\mathrm{C}_{2} \mathrm{H}_{5} \mathrm{OH} \rightarrow \mathrm{C}_{2} \mathrm{H}_{5} \mathrm{O}^{+}+\mathrm{CH}_{4}$

followed by

$\mathrm{C}_{2} \mathrm{H}_{5} \mathrm{O}^{+}+\mathrm{e}^{-} \rightarrow \mathrm{C}_{2} \mathrm{H}_{4} \mathrm{O}+\mathrm{H}$.

Following the same trend as EO, we also assumed that all the isomers of $\mathrm{PrO}$ could also be produced by the $\mathrm{DR}$ of $\mathrm{C}_{3} \mathrm{H}_{7} \mathrm{O}^{+}$ with the same rate. The formation of $\mathrm{C}_{3} \mathrm{H}_{7} \mathrm{O}^{+}\left(\mathrm{CH}_{3} \mathrm{COCH}_{4}{ }^{+}\right.$; 
i.e., protonated acetone or ethyl, 1- methoxy-, ion) was already included in the UMIST 2012 network, so we did not use any additional channel to form this ion. Instead, only the destruction of this ion by the DR is considered.

\subsection{Formation by suprathermal oxygen}

Recently, Bergantini et al. (2018) carried out a combined theoretical and experimental work to study the formation of interstellar PrO. They found that the galactic, cosmic-ray-induced ice phase chemistry with suprathermal oxygen $\left(\mathrm{O}^{*}\right.$ or $\left.\mathrm{O}\left({ }^{1} \mathrm{D}\right)\right)$ may lead to the significant amount of PrO (R17 of Table 1). For the generation of suprathermal oxygen, they considered the dissociation of $\mathrm{CO}_{2}, \mathrm{H}_{2} \mathrm{O}$, and $\mathrm{CO}$. The rate constants of the radiolysis were calculated using the following relation:

$R=\frac{\zeta}{10^{-17}\left[\mathrm{~s}^{-1}\right]} \frac{G}{100[\mathrm{eV}]} S_{\mathrm{e}} \phi_{\mathrm{ism}} \quad \mathrm{s}^{-1}$,

where, $G$ is the radiolysis yield per $100 \mathrm{eV}, S_{\mathrm{e}}$ is the electronic stopping cross section, $\Phi_{\text {ism }}$ is the interstellar cosmic-ray flux and $\zeta$ is the cosmic-ray ionization rate. We used same $G$ value as used in Bergantini et al. (2018) (2.23, 0.7, and 0.8 for $\mathrm{CO}_{2}, \mathrm{H}_{2} \mathrm{O}$, and $\mathrm{CO}$, respectively), $\phi_{\text {ism }}=10 \mathrm{~cm}^{-2} \mathrm{~s}^{-1}$ following Abplanalp et al. (2016). We used $\zeta=1.3 \times 10^{-17} \mathrm{~s}^{-1}$ instead of $1.3 \times 10^{-16}$ used in Bergantini et al. (2018). Although Abplanalp et al. (2016) mentioned that $S_{\mathrm{e}}$ is the electron stopping cross section for electrons, Bergantini et al. (2018) used $S_{\mathrm{e}}$ as the electron stopping cross section for protons from the PSTAR program ${ }^{1}$. We used ESTAR program ${ }^{2}$ as used by Abplanalp et al. (2016) for the computation of the $S_{\mathrm{e}}$ parameter. Since, $S_{\mathrm{e}}$ is sensitive to the projectile energy, for a better approximation for $S_{\mathrm{e}}$, we used projectile energy of the electron $1 \mathrm{KeV}$ (minimum available value in the ESTAR program), $5 \mathrm{KeV}$, and $10 \mathrm{KeV}$, respectively, and considered their average. We found $S_{\mathrm{e}}=3.62 \times 10^{-15}, 1.80 \times 10^{-15}$, and $2.34 \times 10^{-15} \mathrm{ev} \mathrm{cm}^{2}$ molecule ${ }^{-1}$ when we used $\mathrm{CO}_{2}, \mathrm{H}_{2} \mathrm{O}$, and $\mathrm{CO}$ ice as target materials, respectively. For the density of the target materials, we used $1.3,1$, and $0.81 \mathrm{gm} \mathrm{cm}^{-3}$ for $\mathrm{CO}_{2}, \mathrm{H}_{2} \mathrm{O}$, and CO ice, respectively, from Lauck et al. (2015) and references therein. By considering these $S_{\text {e }}$ parameters, we obtained rate constants of $1.05 \times 10^{-13}, 1.64 \times 10^{-14}$, and $2.43 \times 10^{-14} \mathrm{~s}^{-1}$ for $\mathrm{CO}_{2}, \mathrm{H}_{2} \mathrm{O}$, and $\mathrm{CO}$ ice, respectively, as a target material.

For the consideration of the suprathermal oxygen $\left(\mathrm{O}\left({ }^{1} \mathrm{D}\right)\right)$ in our network, we considered some trivial approximations. After the generation of these suprathermal oxygens, they are treated similarly as the $\mathrm{O}\left({ }^{3} \mathrm{P}\right)$, except the reaction with $\mathrm{C}_{3} \mathrm{H}_{6}$. For the reaction between $\mathrm{C}_{3} \mathrm{H}_{6}$ and $\mathrm{O}\left({ }^{1} \mathrm{D}\right)$, we assumed that the reaction is barrierless in nature and process in each encounter. The binding energy of the $\mathrm{O}\left({ }^{1} \mathrm{D}\right)$ is assumed to be the same as $\mathrm{O}\left({ }^{3} \mathrm{P}\right)$ and supposed to behave similarly in the gas phase upon its sublimation. We did not consider the $\mathrm{O}\left({ }^{1} \mathrm{D}\right)$ insertion reactions for any other species in our network. We used these reactions only for the formation of PrO. We tested the effect of these oxygen insertion reactions on the abundances of the major species, which remain mostly unaltered.

\subsection{Destruction pathways}

All the destruction pathways for the PrO along with its isomers are shown in Table 3. We considered IN reactions for the destruction of PrO and its isomers. The most abundant ions

\footnotetext{
1 https://physics.nist.gov/PhysRefData/Star/Text/ PSTAR.html

2 https://physics.nist.gov/PhysRefData/Star/Text/ ESTAR.html
}

like, $\mathrm{C}^{+}, \mathrm{H}^{+}, \mathrm{He}^{+}, \mathrm{H}_{3}^{+}, \mathrm{H}_{3} \mathrm{O}^{+}$, and $\mathrm{HCO}^{+}$have been considered (Occhiogrosso et al. 2012). Additionally, DR, photodissociation $(\mathrm{PH})$, and dissociation by cosmic rays $(\mathrm{CRPH})$ have also been considered for the destruction. Ion-neutral reactions are very efficient for the destruction of neutral interstellar species. If the neutral species is nonpolar, we used the Langevin collision rate coefficient (Herbst 2006; Wakelam et al. 2010) and if the neutral species is polar, then we employed the trajectory scaling relation (Su \& Chesnavich 1982; Woon \& Herbst 2009). For the destruction by photoreactions, we used the following equation:

$k_{\mathrm{PH}}=\alpha \exp \left(-\gamma A_{\mathrm{V}}\right)$

where $\alpha$ is the rate coefficient $\left(\mathrm{s}^{-1}\right)$ in the unshielded interstellar ultraviolet radiation field, $A_{\mathrm{V}}$ is the visual extinction, and $\gamma$ controls the extinction of the dust at the ultraviolet wavelength. We used $\alpha=1.13 \times 10^{-09} \mathrm{~s}^{-1}$ and $\gamma=1.6$ for the $\mathrm{PH}$ of $\mathrm{CH}_{3} \mathrm{CHCH}_{2}$.

For the cosmic-ray-induced photoreactions, we used the following relation (Gredel et al. 1989):

$k_{\mathrm{CRPH}}=\alpha \gamma^{\prime} /(1-\omega)$,

where, $\alpha$ is the cosmic-ray ionization rate $\left(\mathrm{s}^{-1}\right), \gamma^{\prime}$ is the number of photodissociative events that take place per cosmic-ray ionization and $\omega$ is the dust grain albedo in the far ultraviolet. We used $\omega=0.6, \alpha=1.3 \times 10^{-17} \mathrm{~s}^{-1}$, and $\gamma^{\prime}=750.0$ by following the cosmic-ray-induced photoreactions of $\mathrm{CH}_{3} \mathrm{OH}$ in Woodall et al. (2007).

\section{Chemical modeling}

We used our large gas-grain chemical network (Das et al. 2008b, 2013a,b, 2015a,b; Majumdar et al. 2014a,b; Gorai et al. 2017a,b) to estimate the formation of $\mathrm{PrO}$ in the star-forming region. The gas phase chemical network is mainly adopted from the UMIST 2012 database (McElroy et al. 2013) and the grain surface chemical network is primarily developed from Ruaud et al. (2016). As the initial elemental abundances (Table 4), we considered the "low metal" abundance with C/O ratio $\sim 0.607$ (Hincelin et al. 2011), which are often used for the modeling of dense clouds, where the majority of the hydrogen atoms are locked in the form of hydrogen molecules.

\subsection{Dark cloud model}

\subsubsection{Physical condition}

To mimic the observed region of the $\mathrm{PrO}$, we considered a total hydrogen number density $\left(n_{\mathrm{H}}\right)=2 \times 10^{4} \mathrm{~cm}^{-3}$ and a gas temperature $\left(T_{\text {gas }}\right)=30 \mathrm{~K}$ and dust temperature $\left(T_{\text {ice }}\right)=10$ and $25 \mathrm{~K}$, respectively. We assumed a visual extinction parameter $\left(A_{\mathrm{V}}\right)$ of 30 and considered a cosmic-ray ionization rate $(\zeta)$ of $1.3 \times 10^{-17} \mathrm{~s}^{-1}$ (Herbst \& Klemperer 1973). Since reactive desorption (Garrod et al. 2007) is a very efficient means to transfer surface species into the gas phase upon formation, we considered this in our model.

\subsubsection{Results and discussions}

Chemical evolution of $\mathrm{PrO}$ and $\mathrm{C}_{3} \mathrm{H}_{6}$ is shown in Fig. 2. The left panel of Fig. 2 is for $T_{\text {ice }}=10 \mathrm{~K}$ and right panel is for $T_{\text {ice }}=$ $25 \mathrm{~K}$. The left panel depicts two scenarios: one scenario has a fiducial reactive desorption parameter of $a=0.03$ and the other has that of $a=0$; unless otherwise stated, we always used this 
Table 3. Destruction pathways of $\mathrm{PrO}$ and its isomers.

\begin{tabular}{|c|c|c|c|c|c|}
\hline $\begin{array}{l}\text { Reaction } \\
\text { number } \\
\text { (type) }\end{array}$ & Reaction & $\alpha$ & $\beta$ & $\gamma$ & Rate coefficient@30 K \\
\hline R1 (IN) & $\mathrm{C}^{+}+\mathrm{C}_{3} \mathrm{H}_{6} \mathrm{O} \rightarrow \mathrm{C}_{3} \mathrm{H}_{6} \mathrm{O}^{+}+\mathrm{C}$ & $1.50 \times 10^{-9}$ & -0.5 & 0.0 & $4.74 \times 10^{-09}$ \\
\hline R2 (IN) & $\mathrm{C}^{+}+\mathrm{CH}_{3} \mathrm{CH}_{2} \mathrm{CHO} \rightarrow \mathrm{C}_{3} \mathrm{H}_{6} \mathrm{O}^{+}+\mathrm{C}$ & $1.50 \times 10^{-9}$ & -0.5 & 0.0 & $4.74 \times 10^{-09}$ \\
\hline R3 (IN) & $\mathrm{C}^{+}+\mathrm{CH}_{3} \mathrm{CHCHOH} \rightarrow \mathrm{C}_{3} \mathrm{H}_{6} \mathrm{O}^{+}+\mathrm{C}$ & $1.50 \times 10^{-9}$ & -0.5 & 0.0 & $4.74 \times 10^{-09}$ \\
\hline R4 (IN) & $\mathrm{C}^{+}+\mathrm{CH}_{3} \mathrm{COHCH}_{2} \rightarrow \mathrm{C}_{3} \mathrm{H}_{6} \mathrm{O}^{+}+\mathrm{C}$ & $1.50 \times 10^{-9}$ & -0.5 & 0.0 & $4.74 \times 10^{-09}$ \\
\hline R5 (IN) & $\mathrm{C}^{+}+\mathrm{C}_{3} \mathrm{H}_{6} \mathrm{O} \rightarrow \mathrm{C}_{3} \mathrm{H}_{5} \mathrm{O}^{+}+\mathrm{CH}$ & $1.50 \times 10^{-9}$ & -0.5 & 0.0 & $4.74 \times 10^{-09}$ \\
\hline R6 (IN) & $\mathrm{C}^{+}+\mathrm{CH}_{3} \mathrm{CH}_{2} \mathrm{CHO} \rightarrow \mathrm{C}_{3} \mathrm{H}_{5} \mathrm{O}^{+}+\mathrm{CH}$ & $1.50 \times 10^{-9}$ & -0.5 & 0.0 & $4.74 \times 10^{-09}$ \\
\hline R7 (IN) & $\mathrm{C}^{+}+\mathrm{CH}_{3} \mathrm{CHCHOH} \rightarrow \mathrm{C}_{3} \mathrm{H}_{5} \mathrm{O}^{+}+\mathrm{CH}$ & $1.50 \times 10^{-9}$ & -0.5 & 0.0 & $4.74 \times 10^{-09}$ \\
\hline R8 (IN) & $\mathrm{C}^{+}+\mathrm{CH}_{3} \mathrm{COHCH}_{2} \rightarrow \mathrm{C}_{3} \mathrm{H}_{5} \mathrm{O}^{+}+\mathrm{CH}$ & $1.50 \times 10^{-9}$ & -0.5 & 0.0 & $4.74 \times 10^{-09}$ \\
\hline R9 (IN) & $\mathrm{H}^{+}+\mathrm{C}_{3} \mathrm{H}_{6} \mathrm{O} \rightarrow \mathrm{C}_{3} \mathrm{H}_{6} \mathrm{O}^{+}+\mathrm{H}$ & $3.60 \times 10^{-9}$ & -0.5 & 0.0 & $1.13 \times 10^{-08}$ \\
\hline R10 (IN) & $\mathrm{H}^{+}+\mathrm{CH}_{3} \mathrm{CH}_{2} \mathrm{CHO} \rightarrow \mathrm{C}_{3} \mathrm{H}_{6} \mathrm{O}^{+}+\mathrm{H}$ & $3.60 \times 10^{-9}$ & -0.5 & 0.0 & $1.13 \times 10^{-08}$ \\
\hline R11 (IN) & $\mathrm{H}^{+}+\mathrm{CH}_{3} \mathrm{CHCHOH} \rightarrow \mathrm{C}_{3} \mathrm{H}_{6} \mathrm{O}^{+}+\mathrm{H}$ & $3.60 \times 10^{-9}$ & -0.5 & 0.0 & $1.13 \times 10^{-08}$ \\
\hline R12 (IN) & $\mathrm{H}^{+}+\mathrm{CH}_{3} \mathrm{COHCH}_{2} \rightarrow \mathrm{C}_{3} \mathrm{H}_{6} \mathrm{O}^{+}+\mathrm{H}$ & $3.60 \times 10^{-9}$ & -0.5 & 0.0 & $1.13 \times 10^{-08}$ \\
\hline R13 (IN) & $\mathrm{H}^{+}+\mathrm{C}_{3} \mathrm{H}_{6} \mathrm{O} \rightarrow \mathrm{C}_{3} \mathrm{H}_{5} \mathrm{O}^{+}+\mathrm{H}$ & $3.60 \times 10^{-9}$ & -0.5 & 0.0 & $1.13 \times 10^{-08}$ \\
\hline R14 (IN) & $\mathrm{H}^{+}+\mathrm{CH}_{3} \mathrm{CH}_{2} \mathrm{CHO} \rightarrow \mathrm{C}_{3} \mathrm{H}_{5} \mathrm{O}^{+}+\mathrm{H}$ & $3.60 \times 10^{-9}$ & -0.5 & 0.0 & $1.13 \times 10^{-08}$ \\
\hline R15 (IN) & $\mathrm{H}^{+}+\mathrm{CH}_{3} \mathrm{CHCHOH} \rightarrow \mathrm{C}_{3} \mathrm{H}_{5} \mathrm{O}^{+}+\mathrm{H}$ & $3.60 \times 10^{-9}$ & -0.5 & 0.0 & $1.13 \times 10^{-08}$ \\
\hline R16 (IN) & $\mathrm{H}^{+}+\mathrm{CH}_{3} \mathrm{COHCH}_{2} \rightarrow \mathrm{C}_{3} \mathrm{H}_{5} \mathrm{O}^{+}+\mathrm{H}$ & $3.60 \times 10^{-9}$ & -0.5 & 0.0 & $1.13 \times 10^{-08}$ \\
\hline R17 (IN) & $\mathrm{He}^{+}+\mathrm{C}_{3} \mathrm{H}_{6} \mathrm{O} \rightarrow \mathrm{HCO}+\mathrm{C}_{2} \mathrm{H}_{5}^{+}+\mathrm{He}$ & $3.00 \times 10^{-9}$ & -0.5 & 0.0 & $9.48 \times 10^{-09}$ \\
\hline R18 (IN) & $\mathrm{He}^{+}+\mathrm{CH}_{3} \mathrm{CH}_{2} \mathrm{CHO} \rightarrow \mathrm{HCO}+\mathrm{C}_{2} \mathrm{H}_{5}^{+}+\mathrm{He}$ & $3.00 \times 10^{-9}$ & -0.5 & 0.0 & $9.48 \times 10^{-09}$ \\
\hline R19 (IN) & $\mathrm{He}^{+}+\mathrm{CH}_{3} \mathrm{CHCHOH} \rightarrow \mathrm{HCO}+\mathrm{C}_{2} \mathrm{H}_{5}^{+}+\mathrm{He}$ & $3.00 \times 10^{-9}$ & -0.5 & 0.0 & $9.48 \times 10^{-09}$ \\
\hline R20 (IN) & $\mathrm{He}^{+}+\mathrm{CH}_{3} \mathrm{COHCH}_{2} \rightarrow \mathrm{HCO}+\mathrm{C}_{2} \mathrm{H}_{5}^{+}+\mathrm{He}$ & $3.00 \times 10^{-9}$ & -0.5 & 0.0 & $9.48 \times 10^{-09}$ \\
\hline R21 (IN) & $\mathrm{He}^{+}+\mathrm{C}_{3} \mathrm{H}_{6} \mathrm{O} \rightarrow \mathrm{HCO}^{+}+\mathrm{C}_{2} \mathrm{H}_{5}+\mathrm{He}$ & $3.00 \times 10^{-9}$ & -0.5 & 0.0 & $9.48 \times 10^{-09}$ \\
\hline R22 (IN) & $\mathrm{He}^{+}+\mathrm{CH}_{3} \mathrm{CH}_{2} \mathrm{CHO} \rightarrow \mathrm{HCO}^{+}+\mathrm{C}_{2} \mathrm{H}_{5}+\mathrm{He}$ & $3.00 \times 10^{-9}$ & -0.5 & 0.0 & $9.48 \times 10^{-09}$ \\
\hline R23 (IN) & $\mathrm{He}^{+}+\mathrm{CH}_{3} \mathrm{CHCHOH} \rightarrow \mathrm{HCO}^{+}+\mathrm{C}_{2} \mathrm{H}_{5}+\mathrm{He}$ & $3.00 \times 10^{-9}$ & -0.5 & 0.0 & $9.48 \times 10^{-09}$ \\
\hline R24 (IN) & $\mathrm{He}^{+}+\mathrm{CH}_{3} \mathrm{COHCH}_{2} \rightarrow \mathrm{HCO}^{+}+\mathrm{C}_{2} \mathrm{H}_{5}+\mathrm{He}$ & $3.00 \times 10^{-9}$ & -0.5 & 0.0 & $9.48 \times 10^{-09}$ \\
\hline R25 (IN) & $\mathrm{H}_{3}^{+}+\mathrm{C}_{3} \mathrm{H}_{6} \mathrm{O} \rightarrow \mathrm{C}_{3} \mathrm{H}_{7} \mathrm{O}^{+}+\mathrm{H}_{2}$ & $4.14 \times 10^{-10}$ & -0.5 & 0.0 & $1.29 \times 10^{-09}$ \\
\hline R26 (IN) & $\mathrm{H}_{3}^{+}+\mathrm{CH}_{3} \mathrm{CH}_{2} \mathrm{CHO} \rightarrow \mathrm{C}_{3} \mathrm{H}_{7} \mathrm{O}^{+}+\mathrm{H}_{2}$ & $4.14 \times 10^{-10}$ & -0.5 & 0.0 & $1.29 \times 10^{-09}$ \\
\hline R27 (IN) & $\mathrm{H}_{3}^{+}+\mathrm{CH}_{3} \mathrm{CHCHOH} \rightarrow \mathrm{C}_{3} \mathrm{H}_{7} \mathrm{O}^{+}+\mathrm{H}_{2}$ & $4.14 \times 10^{-10}$ & -0.5 & 0.0 & $1.29 \times 10^{-09}$ \\
\hline R28 (IN) & $\mathrm{H}_{3}^{+}+\mathrm{CH}_{3} \mathrm{COHCH}_{2} \rightarrow \mathrm{C}_{3} \mathrm{H}_{7} \mathrm{O}^{+}+\mathrm{H}_{2}$ & $4.14 \times 10^{-10}$ & -0.5 & 0.0 & $1.29 \times 10^{-09}$ \\
\hline R29 (IN) & $\mathrm{HCO}^{+}+\mathrm{C}_{3} \mathrm{H}_{6} \mathrm{O} \rightarrow \mathrm{C}_{3} \mathrm{H}_{7} \mathrm{O}^{+}+\mathrm{CO}$ & $3.40 \times 10^{-9}$ & -0.5 & 0.0 & $1.07 \times 10^{-08}$ \\
\hline R30 (IN) & $\mathrm{HCO}^{+}+\mathrm{CH}_{3} \mathrm{CH}_{2} \mathrm{CHO} \rightarrow \mathrm{C}_{3} \mathrm{H}_{7} \mathrm{O}^{+}+\mathrm{CO}$ & $3.40 \times 10^{-9}$ & -0.5 & 0.0 & $1.07 \times 10^{-08}$ \\
\hline R31 (IN) & $\mathrm{HCO}^{+}+\mathrm{CH}_{3} \mathrm{CHCHOH} \rightarrow \mathrm{C}_{3} \mathrm{H}_{7} \mathrm{O}^{+}+\mathrm{CO}$ & $3.40 \times 10^{-9}$ & -0.5 & 0.0 & $1.07 \times 10^{-08}$ \\
\hline R32 (IN) & $\mathrm{HCO}^{+}+\mathrm{CH}_{3} \mathrm{COHCH}_{2} \rightarrow \mathrm{C}_{3} \mathrm{H}_{7} \mathrm{O}^{+}+\mathrm{CO}$ & $3.40 \times 10^{-9}$ & -0.5 & 0.0 & $1.07 \times 10^{-08}$ \\
\hline R33 (IN) & $\mathrm{H}_{3} \mathrm{O}^{+}+\mathrm{C}_{3} \mathrm{H}_{6} \mathrm{O} \rightarrow \mathrm{C}_{3} \mathrm{H}_{7} \mathrm{O}^{+}+\mathrm{H}_{2} \mathrm{O}$ & $3.60 \times 10^{-9}$ & -0.5 & 0.0 & $1.13 \times 10^{-08}$ \\
\hline R34 (IN) & $\mathrm{H}_{3} \mathrm{O}^{+}+\mathrm{CH}_{3} \mathrm{CH}_{2} \mathrm{CHO} \rightarrow \mathrm{C}_{3} \mathrm{H}_{7} \mathrm{O}^{+}+\mathrm{H}_{2} \mathrm{O}$ & $3.60 \times 10^{-9}$ & -0.5 & 0.0 & $1.13 \times 10^{-08}$ \\
\hline R35 (IN) & $\mathrm{H}_{3} \mathrm{O}^{+}+\mathrm{CH}_{3} \mathrm{CHCHOH} \rightarrow \mathrm{C}_{3} \mathrm{H}_{7} \mathrm{O}^{+}+\mathrm{H}_{2} \mathrm{O}$ & $3.60 \times 10^{-9}$ & -0.5 & 0.0 & $1.13 \times 10^{-08}$ \\
\hline R36 (IN) & $\mathrm{H}_{3} \mathrm{O}^{+}+\mathrm{CH}_{3} \mathrm{COHCH}_{2} \rightarrow \mathrm{C}_{3} \mathrm{H}_{7} \mathrm{O}^{+}+\mathrm{H}_{2} \mathrm{O}$ & $3.60 \times 10^{-9}$ & -0.5 & 0.0 & $1.13 \times 10^{-08}$ \\
\hline R37 (DR) & $\mathrm{C}_{3} \mathrm{H}_{6} \mathrm{O}^{+}+\mathrm{e}^{-} \rightarrow \mathrm{C}_{2} \mathrm{H}_{5}+\mathrm{HCO}$ & $1.08 \times 10^{-6}$ & -0.70 & 0.0 & $5.51 \times 10^{-06}$ \\
\hline R38 (DR) & $\mathrm{C}_{3} \mathrm{H}_{6} \mathrm{O}^{+}+\mathrm{e}^{-} \rightarrow \mathrm{CH}_{3} \mathrm{CHCH}_{2}+\mathrm{O}$ & $1.08 \times 10^{-6}$ & -0.70 & 0.0 & $5.51 \times 10^{-06}$ \\
\hline R39 (DR) & $\mathrm{C}_{3} \mathrm{H}_{6} \mathrm{O}^{+}+\mathrm{e}^{-} \rightarrow \mathrm{CH}_{2} \mathrm{CCH}+\mathrm{H}_{2} \mathrm{O}+\mathrm{H}$ & $1.50 \times 10^{-7}$ & -0.50 & 0.0 & $4.74 \times 10^{-07}$ \\
\hline R40 (DR) & $\mathrm{C}_{3} \mathrm{H}_{6} \mathrm{O}^{+}+\mathrm{e}^{-} \rightarrow \mathrm{CH}_{3} \mathrm{CCH}+\mathrm{H}_{2} \mathrm{O}$ & $1.50 \times 10^{-7}$ & -0.50 & 0.0 & $4.74 \times 10^{-07}$ \\
\hline R41 (DR) & $\mathrm{C}_{3} \mathrm{H}_{7} \mathrm{O}^{+}+\mathrm{e}^{-} \rightarrow \mathrm{C}_{2} \mathrm{H}_{4}+\mathrm{H}_{2} \mathrm{CO}+\mathrm{H}$ & $8.47 \times 10^{-7}$ & -0.74 & 0.0 & $4.67 \times 10^{-06}$ \\
\hline R42 (DR) & $\mathrm{C}_{3} \mathrm{H}_{7} \mathrm{O}^{+}+\mathrm{e}^{-} \rightarrow \mathrm{C}_{2} \mathrm{H}_{5}+\mathrm{HCO}+\mathrm{H}$ & $8.47 \times 10^{-7}$ & -0.74 & 0.0 & $4.67 \times 10^{-06}$ \\
\hline R43 (DR) & $\mathrm{C}_{3} \mathrm{H}_{7} \mathrm{O}^{+}+\mathrm{e}^{-} \rightarrow \mathrm{CO}+\mathrm{CH}_{3} \mathrm{CH}_{3}+\mathrm{H}$ & $8.47 \times 10^{-7}$ & -0.74 & 0.0 & $4.67 \times 10^{-06}$ \\
\hline R44 (DR) & $\mathrm{C}_{3} \mathrm{H}_{7} \mathrm{O}^{+}+\mathrm{e}^{-} \rightarrow \mathrm{H}_{2} \mathrm{CO}+\mathrm{C}_{2} \mathrm{H}_{5}$ & $8.47 \times 10^{-7}$ & -0.74 & 0.0 & $4.67 \times 10^{-06}$ \\
\hline R45 (DR) & $\mathrm{C}_{3} \mathrm{H}_{7} \mathrm{O}^{+}+\mathrm{e}^{-} \rightarrow \mathrm{C}_{3} \mathrm{H}_{6}+\mathrm{H}$ & $3.00 \times 10^{-7}$ & -0.74 & 0.0 & $1.64 \times 10^{-06}$ \\
\hline R46 (DR) & $\mathrm{C}_{3} \mathrm{H}_{7} \mathrm{O}^{+}+\mathrm{e}^{-} \rightarrow \mathrm{CH}_{3} \mathrm{CH}_{2} \mathrm{CHO}+\mathrm{H}$ & $3.00 \times 10^{-7}$ & -0.74 & 0.0 & $1.64 \times 10^{-06}$ \\
\hline R47 (DR) & $\mathrm{C}_{3} \mathrm{H}_{7} \mathrm{O}^{+}+\mathrm{e}^{-} \rightarrow \mathrm{CH}_{3} \mathrm{CHCHOH}+\mathrm{H}$ & $3.00 \times 10^{-7}$ & -0.74 & 0.0 & $1.64 \times 10^{-06}$ \\
\hline R48 (DR) & $\mathrm{C}_{3} \mathrm{H}_{7} \mathrm{O}^{+}+\mathrm{e}^{-} \rightarrow \mathrm{CH}_{3} \mathrm{COHCH}_{2}+\mathrm{H}$ & $3.00 \times 10^{-7}$ & -0.74 & 0.0 & $1.64 \times 10^{-06}$ \\
\hline R49 (DR) & $\mathrm{C}_{3} \mathrm{H}_{5} \mathrm{O}^{+}+\mathrm{e}^{-} \rightarrow \mathrm{CH}_{3} \mathrm{CHO}+\mathrm{H}$ & $3.00 \times 10^{-7}$ & -0.74 & 0.0 & $9.48 \times 10^{-07}$ \\
\hline R50 (DR) & $\mathrm{C}_{3} \mathrm{H}_{5} \mathrm{O}^{+}+\mathrm{e}^{-} \rightarrow \mathrm{C}_{2} \mathrm{H}_{5}+\mathrm{CO}$ & $3.00 \times 10^{-7}$ & -0.74 & 0.0 & $9.48 \times 10^{-07}$ \\
\hline R51 (NR) & $\mathrm{CH}_{3} \mathrm{CHCH}_{2}+\mathrm{O} \rightarrow \mathrm{C}_{2} \mathrm{H}_{5}+\mathrm{HCO}$ & $3.6 \times 10^{-12}$ & 0.0 & 0.0 & $3.60 \times 10^{-12}$ \\
\hline R52 (NR) & $\mathrm{CH}_{3} \mathrm{CHCH}_{2}+\mathrm{O} \rightarrow \mathrm{CH}_{3} \mathrm{CO}+\mathrm{CH}_{3}$ & $4.4 \times 10^{-12}$ & 0.0 & 0.0 & $4.40 \times 10^{-12}$ \\
\hline R53 (NR) & $\mathrm{CH}_{2} \mathrm{CHCH}_{2}+\mathrm{N} \rightarrow \mathrm{CH}_{2} \mathrm{CHCN}+\mathrm{H}_{2}$ & $3.2 \times 10^{-11}$ & 0.17 & 0.0 & $2.16 \times 10^{-11}$ \\
\hline R54 (NR) & $\mathrm{CH}_{2} \mathrm{CHCH}_{2}+\mathrm{N} \rightarrow \mathrm{C}_{2} \mathrm{H}_{4}+\mathrm{HCN}$ & $3.2 \times 10^{-11}$ & 0.17 & 0.0 & $2.16 \times 10^{-11}$ \\
\hline R55 (NR) & $\mathrm{CH}_{2} \mathrm{CHCH}_{2}+\mathrm{N} \rightarrow \mathrm{C}_{3} \mathrm{H}_{4}+\mathrm{NH}$ & $1.3 \times 10^{-11}$ & 0.17 & 0.0 & $8.78 \times 10^{-12}$ \\
\hline R56 (NR) & $\mathrm{CH}_{3} \mathrm{CHCH}+\mathrm{N} \rightarrow \mathrm{CH}_{2} \mathrm{CHCN}+\mathrm{H}_{2}$ & $3.2 \times 10^{-11}$ & 0.17 & 0.0 & $2.16 \times 10^{-11}$ \\
\hline R57 (NR) & $\mathrm{CH}_{3} \mathrm{CHCH}+\mathrm{N} \rightarrow \mathrm{C}_{2} \mathrm{H}_{4}+\mathrm{HCN}$ & $3.2 \times 10^{-11}$ & 0.17 & 0.0 & $2.16 \times 10^{-11}$ \\
\hline R58 (NR) & $\mathrm{CH}_{3} \mathrm{CHCH}+\mathrm{N} \rightarrow \mathrm{C}_{3} \mathrm{H}_{4}+\mathrm{NH}$ & $1.3 \times 10^{-11}$ & 0.17 & 0.0 & $8.78 \times 10^{-12}$ \\
\hline $\mathrm{R} 59(\mathrm{PH})$ & $\mathrm{CH}_{3} \mathrm{CHCH}_{2}+$ PHOTON $\rightarrow \mathrm{C}_{2} \mathrm{H}_{4}+\mathrm{CH}_{2}$ & $1.13 \times 10^{-09}$ & 0.00 & 1.6 & $1.56 \times 10^{-30}$ \\
\hline R60 (CRPH) & $\mathrm{CH}_{3} \mathrm{CHCH}_{2}+\mathrm{CR}-\mathrm{PHOTON} \rightarrow \mathrm{C}_{2} \mathrm{H}_{4}+\mathrm{CH}_{2}$ & $1.30 \times 10^{-17}$ & 0.00 & 750 & $1.95 \times 10^{-14}$ \\
\hline
\end{tabular}


Table 4. Initial elemental abundances with respect to total hydrogen nuclei.

\begin{tabular}{cc}
\hline \hline Species & Abundance \\
\hline $\mathrm{H}_{2}$ & $5.00 \times 10^{-01}$ \\
$\mathrm{He}$ & $0.90 \times 10^{-01}$ \\
$\mathrm{~N}$ & $6.20 \times 10^{-05}$ \\
$\mathrm{O}$ & $2.80 \times 10^{-04}$ \\
$\mathrm{C}$ & $1.70 \times 10^{-04}$ \\
$\mathrm{Na}$ & $2.00 \times 10^{-09}$ \\
$\mathrm{Mg}$ & $7.00 \times 10^{-09}$ \\
$\mathrm{Si}$ & $8.00 \times 10^{-09}$ \\
$\mathrm{P}$ & $2.00 \times 10^{-10}$ \\
$\mathrm{~S}$ & $8.00 \times 10^{-08}$ \\
$\mathrm{Cl}$ & $1.00 \times 10^{-09}$ \\
$\mathrm{Fe}$ & $3.00 \times 10^{-09}$ \\
\hline
\end{tabular}

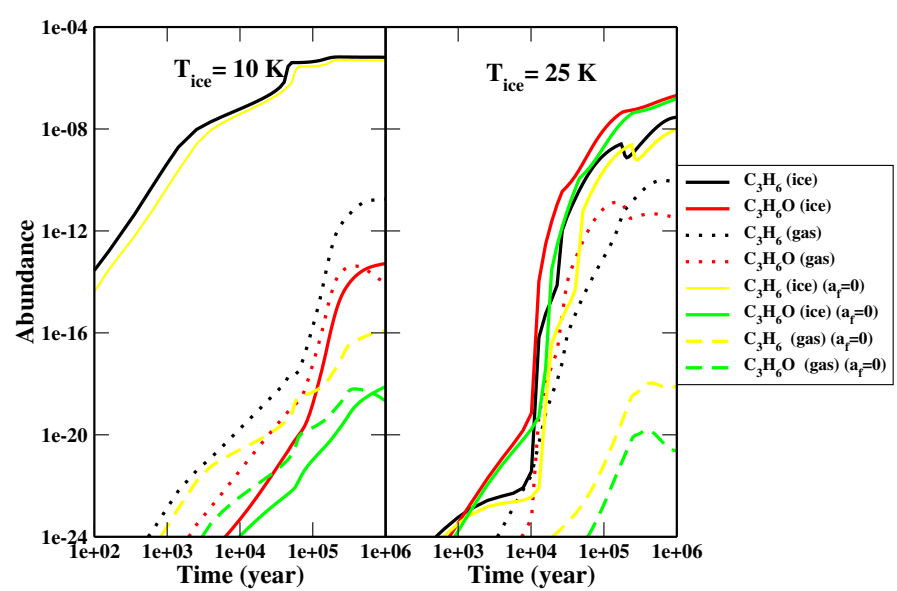

Fig. 2. Chemical evolution of $\mathrm{PrO}$ and $\mathrm{C}_{3} \mathrm{H}_{6}$ for a dark cloud model. The solid line represents ice phase abundance and dotted line represents the gas phase abundance.

value ( $a=0.03$ ) of desorption factor along with the desorption probability 1 (for the reactions producing single product). This shows that when reactive desorption parameter is absent $(a=0)$, the formation of $\mathrm{PrO}$ is insignificant in both the phases. The reason for this is that $\mathrm{C}_{3} \mathrm{H}_{6}$ can efficiently be formed on ice phase but when $a=0.03$ is considered, a significant portion of $\mathrm{C}_{3} \mathrm{H}_{6}$ can be able to transfer to the gas phase, which is not possible for $a=0$. Woodall et al. (2007) considered barrierless reactions for the formation of $\mathrm{C}_{3} \mathrm{H}_{5}{ }^{+}$and $\mathrm{C}_{3} \mathrm{H}_{7}{ }^{+}$in gas phase. But it is already discussed in Sect. 2.2 that these two reactions contain high barrier and it is quite problematic to overcome such a high obstacle around low temperature. Moreover, because of high-energy barrier of $\mathrm{O}$ atom $(1660 \mathrm{~K}$ for ground-state oxygen and suprathermal oxygen atom), oxygenation reaction is not as fast as hydrogenation reaction at low temperatures $\left(T_{\text {ice }}=10 \mathrm{~K}\right)$ and thus the ice phase $\mathrm{PrO}$ formation is inadequate at low temperatures. At low temperatures $(\sim 10 \mathrm{~K}) \mathrm{PrO}$ can mainly be formed in the gas phase by the reaction between $\mathrm{O}$ atom and $\mathrm{C}_{3} \mathrm{H}_{6}$, where the major contribution of $\mathrm{C}_{3} \mathrm{H}_{6}$ is coming from the ice. As we increased the temperature (right panel, $T_{\text {ice }}=25 \mathrm{~K}$ ), the situation has changed because of the increase in the mobility of $\mathrm{O}$ atom on grain, which enables a significant production of $\mathrm{PrO}$ on the grain surface. From our dark cloud model (for $a=0.03$ and $T_{\text {ice }}=10 \mathrm{~K}$ ), in between our simulation timescale $\left(\sim 10^{6} \mathrm{yr}\right)$, we have a peak

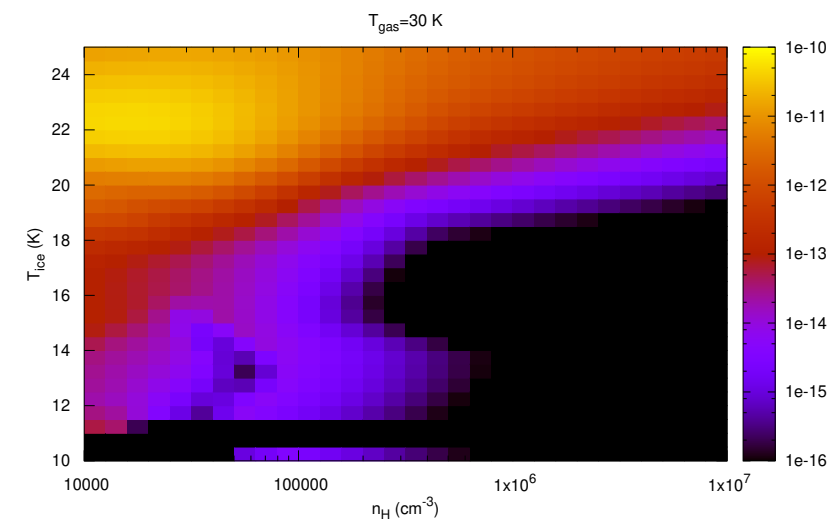

Fig. 3. Parameter space of the abundance of $\mathrm{PrO}$ in dark cloud conditions. The color bar represents the fraction abundance of PrO.

abundance (w.r.t. $\mathrm{H}_{2}$ ) of $\mathrm{PrO}$ to be $4.17 \times 10^{-14}$ and $5.26 \times 10^{-14}$ in the gas and ice phases, respectively, whereas for $a=0.03$ and $T_{\text {ice }}=25 \mathrm{~K}$ it is $1.33 \times 10^{-11}$ and $2.04 \times 10^{-7}$, respectively. In order to check the dependency of our result on the fiducial factor, we further considered $a=0.01$ and $T_{\text {ice }}=25 \mathrm{~K}$ and found that the peak gas phase abundance $\left(\sim 4.58 \times 10^{-12}\right)$ decreased by $\sim 3$ times compared to the case with $a=0.03$ and $T_{\text {ice }}=25 \mathrm{~K}$.

Since, the abundance of $\mathrm{C}_{3} \mathrm{H}_{6}$ in the gas phase is not adequate, no significant amount of $\mathrm{PrO}$ is obtained for $T_{\text {ice }}=10 \mathrm{~K}$ but for $T_{\text {ice }}=25 \mathrm{~K}$, formation of $\mathrm{C}_{3} \mathrm{H}_{6}$ significantly enhanced and resulting significant increase in the production of PrO. To find out a parameter space for the formation of $\mathrm{PrO}$ in the dark cloud condition, we varied the number density of total hydrogen $\left(n_{\mathrm{H}}\right)$ in between $10^{4}$ and $10^{7} \mathrm{~cm}^{-3}$ and ice temperature between 10 and $25 \mathrm{~K}$ and kept the gas temperature at $30 \mathrm{~K}$. The resulting plot is shown in Fig. 3. It is clear from the plot that the observed abundance (approximately $\times 10^{-11}$ ) of PrO can be obtained in between $n_{\mathrm{H}}=10^{4}-10^{5} \mathrm{~cm}^{-3}$ and the ice temperature range from 20 to $25 \mathrm{~K}$.

Since we considered a small activation barrier of about $40 \mathrm{~K}$ for the ice phase reaction between $\mathrm{C}_{3} \mathrm{H}_{6}$ and $\mathrm{O}\left({ }^{3} \mathrm{P}\right)$, consideration of suprathermal oxygen has not influenced our results. It is important to keep in mind that because of the unavailability of the binding energy values for $\mathrm{O}\left({ }^{1} \mathrm{D}\right)$, we considered the same binding energy as that for $\mathrm{O}\left({ }^{3} \mathrm{P}\right)$. However, it is expected that because of the generation process of the suprathermal oxygen, it would carry some extra energy which would enable it to move much faster than $\mathrm{O}\left({ }^{3} \mathrm{P}\right)$. Thus, it is expected that the binding energy of $\mathrm{O}\left({ }^{1} \mathrm{D}\right)$ would be lower than $\mathrm{O}\left({ }^{3} \mathrm{P}\right)$. We tested the abundance of $\mathrm{PrO}$ again by considering a lower binding energy value (half of the normal oxygen) for $\mathrm{O}\left({ }^{1} \mathrm{D}\right)$. However, again for this case, we did not find any significant difference. The reason behind is that, on the one hand, lower binding energy provides much faster diffusion rate and enhances the chance of recombination, but on the other hand, it gives much quicker sublimation rate. This decreases the residence time of $\mathrm{O}\left({ }^{1} \mathrm{D}\right)$ on the grain surface and thus reduces the chance of recombination. Since in our network, $\mathrm{PrO}$ mainly formed by the reaction between $\mathrm{C}_{3} \mathrm{H}_{6}$ and $\mathrm{O}\left({ }^{3} \mathrm{P}\right)$, lowering the binding energy of $\mathrm{O}\left({ }^{1} \mathrm{D}\right)$ did not change our PrO abundance. A higher dose of cosmic rays would be useful to generate more suprathermal oxygen; this could be helpful in the $\mathrm{PrO}$ formation, but it would also dissociate $\mathrm{PrO}$ as well. We think that the cosmic-ray ionization rate of about $1.3 \times 10^{-17} \mathrm{~s}^{-1}$ used in this work is a standard value for the region in which the three transitions of $\mathrm{PrO}$ were observed. 


\subsection{Hot core model}

\subsubsection{Physical condition}

Cunningham et al. (2007) attempted to observe PrO and glycine in Sgr B2(LMH) and Orion-KL with the MOPRA Telescope. However, they did not detect either species but were able to put an upper limit on the abundances of these two molecules in these sources. They proposed an upper limit of about $6.7 \times 10^{14} \mathrm{~cm}^{-2}$ for the column density of PrO in Sgr B2 (LMH). To estimate the abundance of $\mathrm{PrO}$ in the hot core region, we considered a twophase model as used by Garrod \& Herbst (2006). The first phase is assumed to be isothermal at 10 or $25 \mathrm{~K}$ and lasts for $10^{6} \mathrm{yr}$. For this phase, we considered $A_{\mathrm{V}}=30$ and $\zeta=1.3 \times 10^{-17} \mathrm{~s}^{-1}$. The subsequent phase is assumed to be a warm-up period where the temperature can gradually increase up to $200 \mathrm{~K}$ in $10^{5} \mathrm{yr}$. So our total simulation time is restricted up to a total $1.1 \times 10^{6} \mathrm{yr}$. The number density of the total hydrogen is assumed to be constant $\left(n_{\mathrm{H}}=10^{4}-10^{7} \mathrm{~cm}^{-3}\right)$ in both phases of our simulation.

\subsubsection{Results and discussions}

In Fig. 4, we show the chemical evolution of PrO for various density clouds $\left(n_{\mathrm{H}}=10^{4}-10^{7} \mathrm{~cm}^{-3}\right)$. The last panel shows the abundance variation of peak gas phase abundance and final abundance (i.e., at the end of the simulation the timescale $\sim 1.1 \times 10^{6} \mathrm{yr}$ ) of PrO with the number density variation. In case of the $T_{\text {ice }}=10 \mathrm{~K}$, as we decreased the density, the gas phase abundance of PrO increased slightly and have a maximum $\left(\sim 1.5 \times 10^{-7}\right.$ w.r.t. $\left.\mathrm{H}_{2}\right)$ around $n_{\mathrm{H}}=1 \times 10^{4} \mathrm{~cm}^{-3}$. In the highdensity region $\left(\sim 10^{7} \mathrm{~cm}^{-3}\right)$, we obtained the peak abundance $\sim 1.3 \times 10^{-9}$. The final abundance for this case varies between $1.4 \times 10^{-10}$ and $8.9 \times 10^{-8}$. In case of $T_{\text {ice }}=25 \mathrm{~K}$, the peak and final abundance roughly remain invariant; the peak abundance varies between $1.03 \times 10^{-7}$ and $2.4 \times 10^{-7}$ and final abundance varies between $1.7 \times 10^{-8}$ and $3.5 \times 10^{-8}$.

\subsection{Comparison with the previous modeling results}

There are some basic differences between the model described above and those used by the other authors to explain the observed abundance of PrO. Recently, Bergantini et al. (2018) have used a combined experimental and theoretical study to explain the abundance of $\mathrm{PrO}$ in the ISM. They have explained the formation of $\mathrm{PrO}$ by nonequilibrium reactions initiated by the effects of secondary electrons. More specifically, they used suprathermal $\left({ }^{1} \mathrm{D}\right)$ oxygen insertion reaction with propylene to explain the $\mathrm{PrO}$ formation. They did not consider the formation of PrO by the addition of ground state oxygen $\left({ }^{3} \mathrm{P}\right)$. In our case, we considered the formation of PrO by both types of oxygen atoms. Ward \& Price (2011) found a low activation barrier $(\sim 40 \mathrm{~K})$ for the ice phase reaction between $\mathrm{C}_{3} \mathrm{H}_{6}$ and $\mathrm{O}\left({ }^{3} \mathrm{P}\right)$. Such a low activation barrier could be overcome at low temperatures. As a result, we found an adequate production of $\mathrm{PrO}$ even in absence of the suprathermal oxygen insertion reaction.

\section{Vibrational spectroscopy}

\subsection{Methodology}

To compute the vibrational transitions of $\mathrm{PrO}$ and its protonated form, we used the Gaussian 09 program. We used the DFT with 6-311G basis set including diffuse and polarization functions for these calculations. Initially, we verified our results with various methods and basis sets and compared it with the experimentally
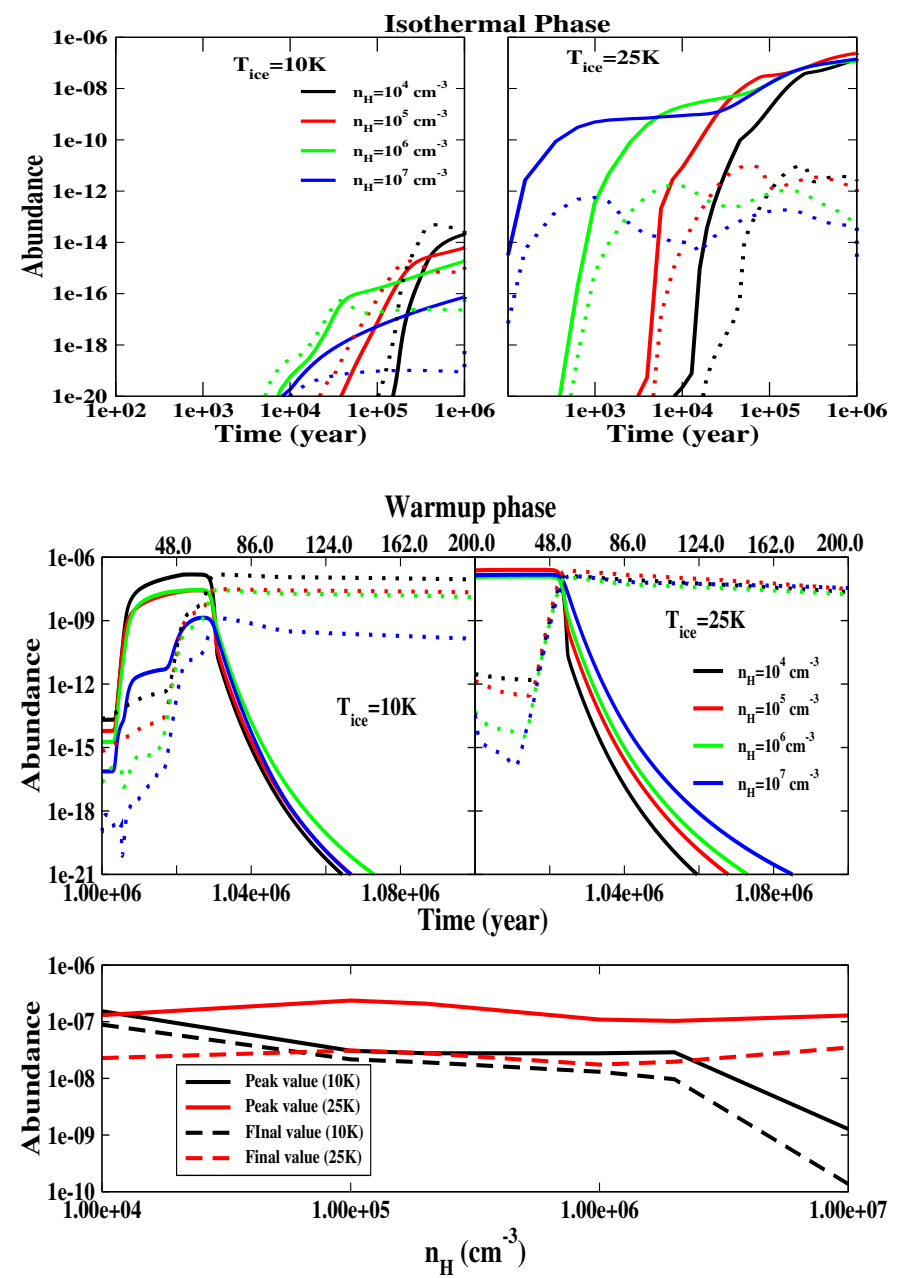

Fig. 4. Chemical evolution of PrO in a two-phase model by considering various cloud densities. The upper two panels indicate the isothermal phase, the middle two panels indicate the warm-up, and the lower panel is for the gas phase peak abundance of $\mathrm{PrO}$ and final abundance of $\mathrm{PrO}$ at the warm-up phase for various density cloud. Different colors denote different cloud densities. In the upper and middle panels, the solid line represents the abundance in the gas phase whereas the dotted line represents the abundance in ice phase.

obtained results. We found that B3LYP/6-311++G(d, p) method is best suited to reproduce the experimentally obtained transitions of PrO. Moreover, we also considered IEPCM model with the method mentioned above to compute the vibrational transitions of $\mathrm{PrO}$ in the ice phase. All optimized geometry was verified by harmonic frequency analysis (having no negative frequency). We performed our calculations by placing the solute (species) in the cavity within the solvent (water molecule) reaction field. We used the SCRF method following the earlier study of Woon (2002).

\subsection{Results and discussions}

In Table 5, we summarized calculated and experimental vibrational frequencies of $\mathrm{PrO}$ along with the integral absorption coefficients and band assignments. Similarly, Table 6 presents the determined vibrational frequencies along with the integral absorption coefficient of protonated PrO. Our calculated values of absorption coefficients and vibrational frequencies are in excellent agreement with the experimentally obtained results (Hudson et al. 2017). Puzzarini et al. (2014) studied the 
Table 5. Vibrational analysis of propylene oxide using B3LYP/6$311++\mathrm{G}(\mathrm{d}, \mathrm{p})$.

\begin{tabular}{|c|c|c|c|c|}
\hline \multicolumn{2}{|c|}{ Wavenumber } & \multirow{2}{*}{$\begin{array}{l}\text { Integral } \\
\text { absorbance } \\
\text { coefficient }(\mathrm{cm} \\
\left.\text { molecule }^{-1}\right)\end{array}$} & \multirow[t]{2}{*}{ Band assignment } & \multirow{2}{*}{$\begin{array}{l}\text { Exp. } \\
\text { value } \\
\text { (Hudso } \\
\text { et al. } \\
\text { 2017) }\end{array}$} \\
\hline$v\left(\mathrm{~cm}^{-1}\right)$ & $\lambda(\mu \mathrm{m})$ & & & \\
\hline 218.85 & 45.84 & $1.31 \times 10^{-19}$ & $\mathrm{CH}_{3}$ torsion & \\
\hline 367.62 & 27.20 & $1.23 \times 10^{-18}$ & $\mathrm{CCC}$ bending & \\
\hline 411.41 & 24.30 & $1.19 \times 10^{-18}$ & CCO bending & \\
\hline 752.24 & 13.29 & $\begin{array}{l}2.47 \\
(1.43)^{(a)} \times 10^{-18}\end{array}$ & ring deformation & 742.0 \\
\hline 826.19 & 12.10 & $\begin{array}{l}15.6 \\
(9.53)^{(a)} \times 10^{-18}\end{array}$ & ring deformation & 825.9 \\
\hline 905.22 & 11.04 & $\begin{array}{l}8.69 \\
(4.8)^{(a)} \times 10^{-19}\end{array}$ & $\mathrm{CH}_{2}$ rocking & 896.7 \\
\hline 961.52 & 10.40 & $\begin{array}{l}4.23 \\
(2.35)^{(a)} \times 10^{-18}\end{array}$ & $\begin{array}{l}\mathrm{CC} \text { stretching or } \mathrm{CH}_{3} \\
\text { rocking }\end{array}$ & 948.3 \\
\hline 1038.38 & 9.63 & $\begin{array}{l}3.08 \\
(2.46)^{(a)} \times 10^{-18}\end{array}$ & $\mathrm{CH}_{3}$ wagging & 1027.3 \\
\hline 1119.31 & 8.93 & $2.01 \times 10^{-18}$ & $\mathrm{CH}_{2}$ rocking & \\
\hline 1149.97 & 8.69 & $8.84 \times 10^{-19}$ & $\mathrm{CH}_{2}$ wagging & \\
\hline 1163.75 & 8.59 & $8.85 \times 10^{-19}$ & $\mathrm{CH}_{3}$ bending & \\
\hline 1185.69 & 8.43 & $2.54 \times 10^{-19}$ & $\mathrm{CH}$ bending & \\
\hline 1291.89 & 7.74 & $1.52(1.47)^{(a)} \times 10^{-18}$ & $\begin{array}{l}\mathrm{CH} \text { bending, ring } \\
\text { deformation }\end{array}$ & 1266 \\
\hline 1401.63 & 7.13 & $7.90(2.57)^{(a)} \times 10^{-19}$ & $\mathrm{CH}_{3}$ deformation & 1408 \\
\hline 1434.36 & 6.97 & $5.23 \times 10^{-18}$ & CC stretching & \\
\hline 1473.10 & 6.78 & $1.70 \times 10^{-18}$ & $\mathrm{CH}_{3}$ deformation & \\
\hline 1486.40 & 6.72 & $1.78 \times 10^{-18}$ & $\mathrm{CH}_{3}$ deformation & \\
\hline 1520.59 & 6.57 & $1.98 \times 10^{-18}$ & $\mathrm{CH}_{2}$ scissoring & \\
\hline 3027.69 & 3.30 & $3.98 \times 10^{-18}$ & $\begin{array}{l}\mathrm{CH}_{3} \text { symmetric } \\
\text { stretching }\end{array}$ & \\
\hline 3087.79 & 3.24 & $5.92 \times 10^{-18}$ & $\begin{array}{l}\mathrm{CH}_{2} \text { asymmetric } \\
\text { stretching }\end{array}$ & \\
\hline 3089.63 & 3.23 & $4.84 \times 10^{-18}$ & $\begin{array}{l}\mathrm{CH}_{2} \text { symmetric } \\
\text { stretching }\end{array}$ & \\
\hline 3098.32 & 3.22 & $1.12 \times 10^{-18}$ & $\mathrm{CH}$ stretching & \\
\hline 3116.85 & 3.20 & $1.02 \times 10^{-17}$ & $\mathrm{CH}$ stretching & \\
\hline 3179.24 & 3.14 & $5.70 \times 10^{-18}$ & $\begin{array}{l}\mathrm{CH}_{2} \text { asymmetric } \\
\text { stretching }\end{array}$ & \\
\hline
\end{tabular}

References. ${ }^{(a)}$ Hudson et al. (2017).

spectroscopic details of protonated oxirane $\left(\mathrm{C}_{2} \mathrm{H}_{5} \mathrm{O}^{+}\right)$. Similarly, protonation of $\mathrm{PrO}$ can take place. $\mathrm{PrO}$ could be protonated via IN reactions in which the proton is transferred to the neutral. Protonated $\mathrm{PrO}$ may be formed in the gas phase by the reaction of $\mathrm{PrO}$ with the ions such as $\mathrm{H}_{3} \mathrm{O}^{+}, \mathrm{HCO}^{+}$, and $\mathrm{H}_{3}^{+}$. We found a proton affinity of $\mathrm{PrO}$ about $803.169 \mathrm{~kJ} \mathrm{~mol}^{-1}$ by doing quantum chemical calculations (using the HF/6-31G(d) method), which is in excellent agreement with Hunter \& Lias (1998) $\left(803.3 \mathrm{~kJ} \mathrm{~mol}^{-1}\right)$. For another protonated form of PrO, the proton affinity value is found to be $801.827 \mathrm{~kJ} \mathrm{~mol}^{-1}$. Thus, the protonated $\mathrm{PrO}$ shown in Fig. 1c possesses slightly higher energy (about $175 \mathrm{~K}$ ) than protonated PrO shown in Fig. 1 b. Since the experimental data for protonated $\mathrm{PrO}$ are yet to be published based on the accuracy obtained for the vibrational transitions of PrO, the same method and basis set were applied for protonated $\mathrm{PrO}$ to compute the vibrational transitions and integral absorption coefficients. Panels a and b of Fig. 5 depict the absorption spectra of PrO and its protonated form. Figure 5a covers $1600-200 \mathrm{~cm}^{-1}$ region (some parts of the midIR: $2000-400 \mathrm{~cm}^{-1}$ and some parts of the far-IR: $400-50 \mathrm{~cm}^{-1}$ ) and Fig. 5b covers $3800-3000 \mathrm{~cm}^{-1}$ region (i.e., some parts of the near-IR: $12800-2000 \mathrm{~cm}^{-1}$ ).
Table 6. Vibrational analysis of protonated propylene oxide $\left(\mathrm{C}_{3} \mathrm{H}_{6} \mathrm{OH}^{+}\right)$ using B3LYP/6-311++G(d,p).

\begin{tabular}{|c|c|c|c|}
\hline \multicolumn{2}{|c|}{ Wavenumber } & \multirow{2}{*}{$\begin{array}{c}\text { Integral absorbance } \\
\text { coefficient }\left(\mathrm{cm} \text { molecule }{ }^{-1}\right)\end{array}$} & \multirow[t]{2}{*}{ Band assignment } \\
\hline$v\left(\mathrm{~cm}^{-1}\right)$ & $\lambda(\mu \mathrm{m})$ & & \\
\hline 207.33 & 48.23 & $8.78 \times 10^{-20}$ & $\mathrm{CH}_{3}$ torsion \\
\hline 325.32 & 30.73 & $4.77 \times 10^{-18}$ & CCO bending \\
\hline 395.82 & 25.26 & $2.25 \times 10^{-18}$ & CCC bending \\
\hline 494.41 & 20.22 & $9.16 \times 10^{-18}$ & ring deformation \\
\hline 748.95 & 13.35 & $2.56 \times 10^{-17}$ & CO stretching \\
\hline 845.94 & 11.82 & $1.06 \times 10^{-17}$ & OH torsion \\
\hline 894.73 & 11.17 & $1.03 \times 10^{-17}$ & $\mathrm{CC}$ stretching \\
\hline 936.21 & 10.68 & $1.48 \times 10^{-18}$ & $\mathrm{CH}_{3}$ wagging, $\mathrm{CH}_{2}$ torsion \\
\hline 982.36 & 10.17 & $5.08 \times 10^{-18}$ & $\mathrm{CH}_{2}$ rocking, $\mathrm{OH}$ bending \\
\hline 1034.35 & 9.66 & $6.07 \times 10^{-18}$ & $\mathrm{CH}_{3}$ wagging \\
\hline 1134.12 & 8.81 & $1.72 \times 10^{-18}$ & $\mathrm{CH}, \mathrm{CH}_{3}$ bending \\
\hline 1212.99 & 8.24 & $5.40 \times 10^{-19}$ & $\mathrm{CH}_{2}$ wagging \\
\hline 1225.73 & 8.15 & $6.52 \times 10^{-18}$ & $\mathrm{CH}, \mathrm{OH}$ bending \\
\hline 1231.93 & 8.11 & $1.33 \times 10^{-18}$ & $\mathrm{CH}_{3}$ bending \\
\hline 1303.36 & 7.62 & $2.82 \times 10^{-18}$ & CC stretching \\
\hline 1404.63 & 7.11 & $1.43 \times 10^{-18}$ & $\mathrm{CH}_{3}$ deformation \\
\hline 1432.85 & 6.97 & $4.37 \times 10^{-18}$ & $\mathrm{CH}_{3}$ deformation \\
\hline 1463.20 & 6.83 & $3.78 \times 10^{-18}$ & $\mathrm{CH}_{3}$ deformation \\
\hline 1492.42 & 3.30 & $6.70 \times 10^{-18}$ & $\mathrm{CH}_{3}$ deformation \\
\hline 1512.84 & 3.24 & $6.61 \times 10^{-18}$ & $\mathrm{CH}_{2}$ scissoring \\
\hline 3045.28 & 3.28 & $6.32 \times 10^{-20}$ & $\mathrm{CH}_{3}$ symmetric stretching \\
\hline 3113.53 & 3.21 & $5.32 \times 10^{-19}$ & $\mathrm{CH}_{3}$ asymmetric stretching \\
\hline 3146.53 & 3.17 & $7.45 \times 10^{-19}$ & $\mathrm{CH}_{2}$ asymmetric stretching \\
\hline 3165.61 & 3.15 & $5.55 \times 10^{-20}$ & $\mathrm{CH}_{2}$ symmetric stretching \\
\hline 3201.52 & 3.12 & $1.5 \times 10^{-19}$ & $\mathrm{CH}$ stretching \\
\hline 3274.58 & 3.05 & $5.14 \times 10^{-19}$ & $\mathrm{CH}_{2}$ asymmetric stretching \\
\hline 3675.89 & 2.74 & $5.45 \times 10^{-17}$ & $\mathrm{OH}$ stretching \\
\hline
\end{tabular}

\subsection{Comparison with experimentally obtained results}

In the upper and lower panels of Fig. 6a, a comparison between our computed and experimentally obtained vibrational spectra is shown for $(1600-800) \mathrm{cm}^{-1}$ and $(3200-2700) \mathrm{cm}^{-1}$ frequency window, respectively. In these two panels, we also show how the clustering of PrO can affect the computed vibrational spectra of PrO. The blue line in Fig. 6 represents the experimental data extracted from Hudson et al. (2017), whereas the black, red, and green lines represent the calculated spectra with $\mathrm{PrO}$ monomer, $\mathrm{PrO}$ dimer, and $\mathrm{PrO}$ tetramer, respectively. Figure 6a depicts that in the mid-IR region, we have a good agreement between our theoretical and experimental results of Hudson et al. (2017). We noticed that most of the transitions within this mid-IR region are within an error bar of about $10 \mathrm{~cm}^{-1}$. One transition at $1291.89 \mathrm{~cm}^{-1}$ is found to be shifted maximum by $25 \mathrm{~cm}^{-1}$. The intensity of each mode of vibration and the area under the curve of various regime changes with the cluster size of PrO. We noticed that if a scaling factor of 0.9728 is used, there is an excellent agreement around the stretching mode, and thus in Fig. 6b we scaled our computed wavenumber accordingly.

\section{Radiative transfer modeling}

\subsection{Methodology}

In astrochemistry, a major aim of radiative transfer modeling is to extract the molecular abundances from the line spectra at infrared and sub(millimeter) wavelengths. Three different levels of radiative transfer model are in use, which range from the basic local thermodynamic equilibrium (LTE) models to complex nonlocal models in 2D and even more complex models in 3D (Van der Tak 2011).

A simple single excitation temperature model, i.e., LTE modeling was carried out to predict the most probable transition of PrO. We consider LTE modeling to be a good starting point for 

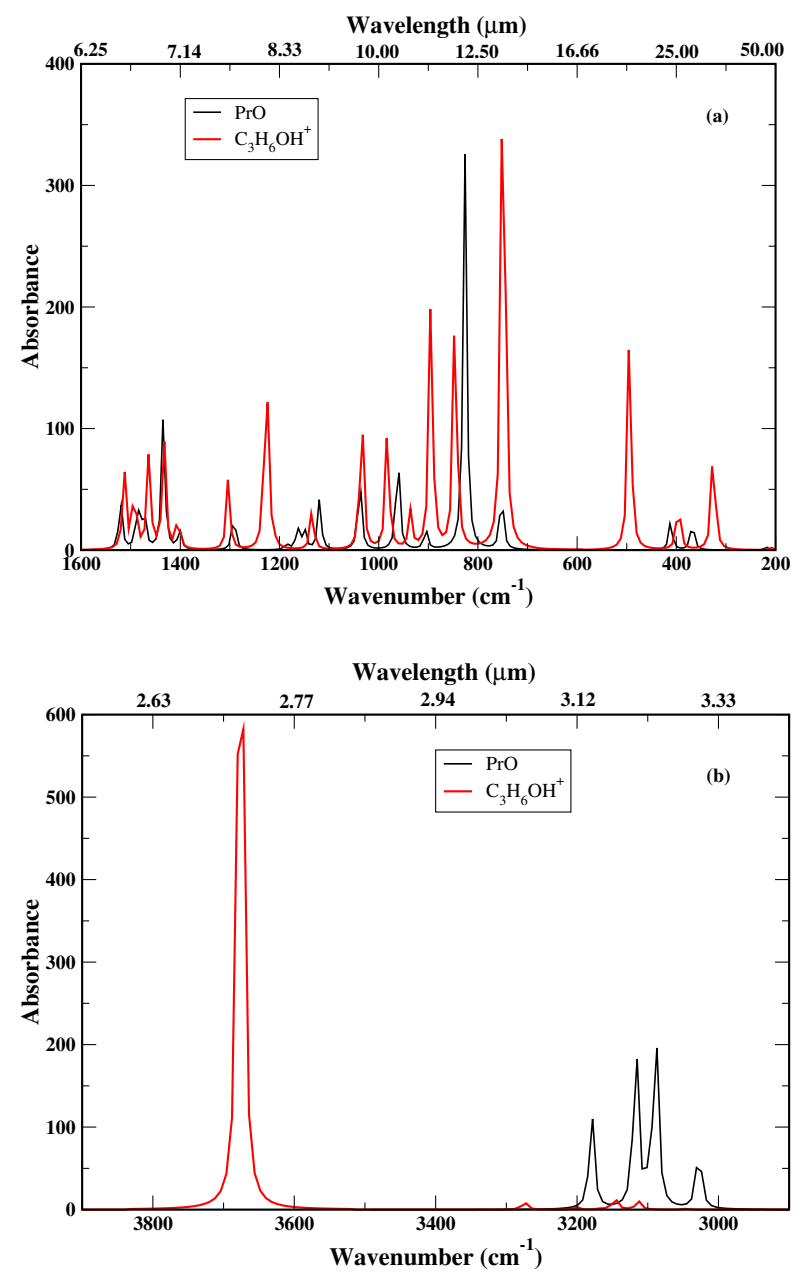

Fig. 5. Comparison between our calculated IR spectra of propylene oxide and protonated propylene oxide.

predicting the line parameters around the high-density region. Moreover, it does not require additional collisional information. We used the CASSIS program, which was developed by IRAP-UPS/CNRS ${ }^{3}$ for the LTE modeling. Recently, McGuire et al. (2016) observed three transitions of PrO in absorption. Cunningham et al. (2007) used the MOPRA telescope at the $3 \mathrm{~mm}$ band for the identification of various transitions of $\mathrm{PrO}$ in Sgr B2(LMH) and Orion-KL. They were unable to detect any PrO transitions in these two targeted regions but they had provided an upper limit for the abundance of $\mathrm{PrO}$ around these sources. We carried out the LTE calculations for two different cases. The first is for the sources in which we are expecting the transitions of $\mathrm{PrO}$ in the extended molecular shell around the embedded, massive protostellar object as observed by McGuire et al. (2016) and for the second, we considered the input parameters in such a way that we may observe some strong transitions of $\mathrm{PrO}$ in the hot core regions as attempted by Cunningham et al. (2007).

In the LTE model, level populations are controlled by Boltzmann distribution. As an interstellar chemical process that is far from thermodynamic equilibrium, it is essential to consider the non-LTE method in which the balance between the excitation and de-excitation of molecular energy levels are explicitly solved. Both the collisional and radiative processes contribute to this balance. Most importantly, for the non-LTE method, the

3 http://cassis.irap.omp.eu
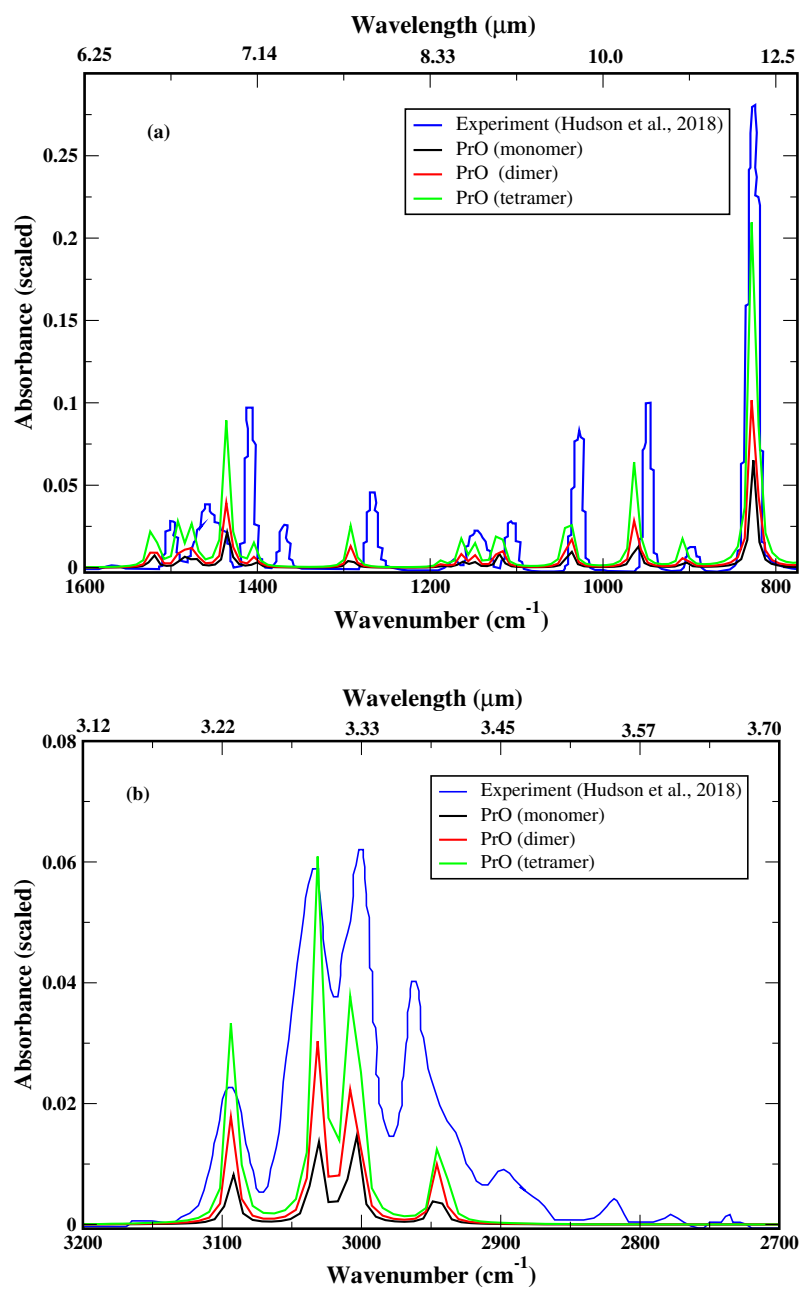

Fig. 6. Comparison between our calculated spectra with those obtained in the experiment (Hudson et al. 2017). The results of Hudson et al. (2017) have been digitally extracted using https://apps. automeris.io/wpd. Upper panel: the mid-IR region. Lower panel: the near-IR region. For the sake of better visualization, we scaled down the $Y$-axis of our calculated values in $(a)$ and $(b)$. Our calculated wavenumber in the $X$-axis of (b) is scaled by 0.9728 to have better agreement.

collisional data file is required that is not available for most of the species. Collisional data file for PrO was not available in any database. To have an educated estimation of the line parameters in non-LTE, we considered the collisional rate parameters of e $-\mathrm{CH}_{3} \mathrm{OH}$ with $\mathrm{H}_{2}$ (Rabli \& Flower 2010) for preparing the collisional data file of PrO. Since PrO is a slightly asymmetric rotor molecule, it would have been better if we used the collisional parameters of $\mathrm{H}_{2} \mathrm{CO}$ in this work. But the unavailability of the collisional rates for the sufficient number of energy levels for $\mathrm{H}_{2} \mathrm{CO}$ tempted us to use $\mathrm{e}-\mathrm{CH}_{3} \mathrm{OH}$ as an approximation for which we have the collisional parameters available in LAMDA database (Schöier et al. 2005) for sufficient number of energy levels. We used the RADEX program (Van der Tak et al. 2007) for this non-LTE computation.

\subsection{Results and discussions}

\subsubsection{LTE model}

For the first case, we considered the GBT $100 \mathrm{~m}$ telescopic parameter for the modeling and adopted parameters are shown in Table 7. For this case, we assumed that the source size $\left(\theta_{\mathrm{s}}\right)$ 
Table 7. Input parameters used for the LTE modeling.

\begin{tabular}{cc}
\hline \multicolumn{2}{c}{ Parameters used for GBT $(100 \mathrm{~m})^{(a)}$} \\
\hline Column density of $\mathrm{H}_{2}$ & $10^{24} \mathrm{~cm}^{-2}$ \\
Column density of propylene oxide & $1.0 \times 10^{13} \mathrm{~cm}^{-2}$ \\
Excitation temperature $\left(T_{\mathrm{ex}}\right)$ & $5 \mathrm{~K}$ \\
Background temperature $\left(T_{\mathrm{C}}\right)$ & $2.73 \mathrm{~K}($ default for LTE $)$ \\
$F W H M$ & $15 \mathrm{~km} \mathrm{~s}^{-1}$ \\
Source size $\left(\theta_{\mathrm{s}}\right)$ & $20^{\prime \prime}$ \\
Beam size $\left(\theta_{\mathrm{b}}\right)$ & $\frac{744}{v}$ \\
Beam dilution & $B=\frac{\theta_{\mathrm{s}}^{2}}{\left(\theta_{\mathrm{s}}^{2}+\theta_{\mathrm{b}}^{2}\right)}$ \\
\hline Parameters used for ALMA $(400 \mathrm{~m})^{(b)}$ \\
\hline Column density of $\mathrm{H}_{2}$ & $10^{24} \mathrm{~cm}^{-2}$ \\
Column density of propylene oxide & $1.74 \times 10^{16} \mathrm{~cm}^{-2}$ \\
Excitation temperature $\left(T_{\mathrm{ex}}\right)$ & $150 \mathrm{~K}^{-}$ \\
Background temperature $\left(T_{\mathrm{C}}\right)$ & $2.73 \mathrm{~K}(\mathrm{default} \mathrm{for} \mathrm{LTE})$ \\
$F W H M$ & $5 \mathrm{~km} \mathrm{~s}^{-1}$ \\
Source size & $3.0^{\prime \prime}$ \\
Beam dilution & 1 \\
\hline
\end{tabular}

References. ${ }^{(a)} \mathrm{GBT}$ model parameters are based on McGuire et al. (2016). ${ }^{(b)}$ ALMA parameters are based on the model of this work.

Table 8. LTE line parameters of the various transitions of PrO using GBT.

\begin{tabular}{ccc}
\hline \hline Frequency $(\mathrm{GHz})$ & $J_{K a^{\prime} k c^{\prime}}-J_{k a^{\prime \prime} k c^{\prime \prime}}$ & Intensity $(\mathrm{mK})$ \\
\hline $12.07243^{\circ}$ & $1_{10}-1_{01}$ & $9.47 \times 10^{-6}$ \\
$12.83734^{\circ}$ & $2_{11}-2_{02}$ & $1.83 \times 10^{-5}$ \\
$14.04776^{\circ}$ & $3_{12}-3_{03}$ & $2.82 \times 10^{-5}$ \\
\hline
\end{tabular}

References. ${ }^{\circ}$ McGuire et al. (2016).

$20^{\prime \prime}$ and beam size $\left(\theta_{\mathrm{b}}\right)$ may vary depending upon the frequency by $\frac{744}{v}$ (Hollis et al. 2007), where $v$ is the frequency in $\mathrm{GHz}$. Beam dilution factor is computed by $B=\frac{\theta_{\mathrm{s}}{ }^{2}}{\left(\theta_{\mathrm{s}}{ }^{2}+\theta_{\mathrm{b}}{ }^{2}\right)}$ and applied on the obtained intensity. The recent observation by McGuire et al. (2016) observed three transitions of PrO in cold molecular shell in front of the bright continuum sources/hot cores within Sgr B2. In Table 8, we point out the obtained LTE parameters for these three transitions only. We noticed that the obtained intensities are very weak and are even below the RMS noise level of $1 \mathrm{mK}$. The reason behind this result is that in the CASSIS module of LTE we used a constant background continuum temperature of $2.73 \mathrm{~K}$. However, a variable background continuum temperature was required to observe these transitions in absorption. We return to the discussion about the absorption feature of these three transitions in a later section of this paper.

For the second case, we modeled the LTE transitions of PrO for the hot core region. We used our computed gas phase PrO abundance $\sim 1.74 \times 10^{-8}$ (final abundance with $n_{\mathrm{H}}=10^{6} \mathrm{~cm}^{-3}$ or $n_{\mathrm{H}_{2}}=5 \times 10^{5} \mathrm{~cm}^{-3}$ with initial dust temperature $25 \mathrm{~K}$ ). We used the Atacama Large Millimeter/submillimeter Array (ALMA) $400 \mathrm{~m}$ telescopic parameter to model this feature. We considered that source size $\left(1.5^{\prime \prime}\right)$ and beam size vary as $\frac{186}{\gamma}$ (for ALMA $400 \mathrm{~m}$ ) and the beam dilution effect applied following the same formula $\left(B=\frac{\theta_{\mathrm{s}}{ }^{2}}{\left(\theta_{\mathrm{s}}{ }^{2}+\theta_{\mathrm{b}}{ }^{2}\right)}\right)$ mentioned above. To verify the potential observability of these PrO transitions, we checked the blending of these transitions with any other interstellar molecular
Table 9. LTE line parameters of the various transitions of PrO using ALMA.

\begin{tabular}{|c|c|c|c|c|c|c|}
\hline $\begin{array}{l}\text { Transition } \\
\left(J_{K a^{\prime} k c^{\prime}}-J_{k a^{\prime \prime} k c^{\prime \prime}}\right)\end{array}$ & $\begin{array}{l}\text { Frequency } \\
(\mathrm{MHz})\end{array}$ & $\begin{array}{l}E_{\mathrm{up}} \\
(\mathrm{K})\end{array}$ & $A_{i j}\left(\mathrm{~s}^{-1}\right)$ & Tau & $\begin{array}{l}\text { Tex } \\
(\mathrm{K})\end{array}$ & $\begin{array}{l}\text { Intensity } \\
(\mathrm{K})\end{array}$ \\
\hline $16215-16116$ & 85166.334 & 83.96 & $2.4 \mathrm{E}-06$ & $1.30 \mathrm{E}-02$ & 150 & 0.58 \\
\hline $717-616$ & 85484.159 & 17.01 & $3.0 \mathrm{E}-06$ & $1.13 \mathrm{E}-02$ & 150 & 0.51 \\
\hline $17414-17315$ & 85856.007 & 102.12 & $5.5 \mathrm{E}-06$ & $2.73 \mathrm{E}-02$ & 150 & 1.23 \\
\hline $422-313$ & $88348.483^{(a)}$ & 8.33 & $3.8 \mathrm{E}-06$ & $8.63 \mathrm{E}-03$ & 150 & 0.39 \\
\hline $735-634$ & 88654.935 & 22.06 & $2.8 \mathrm{E}-06$ & $9.49 \mathrm{E}-03$ & 150 & 0.43 \\
\hline $744-643$ & 88599.017 & 25.98 & $2.3 \mathrm{E}-06$ & 7.62E-03 & 150 & 0.35 \\
\hline $743-642$ & 88601.917 & 25.98 & $2.3 \mathrm{E}-06$ & $7.62 \mathrm{E}-03$ & 150 & 0.35 \\
\hline $716-615$ & 90475.090 & 17.98 & $3.5 \mathrm{E}-06$ & $1.19 \mathrm{E}-02$ & 150 & 0.55 \\
\hline $17216-17117$ & 90723.178 & 94.08 & $2.8 \mathrm{E}-06$ & $1.30 \mathrm{E}-02$ & 150 & 0.65 \\
\hline $717-606$ & $91337.880^{(a),(b)}$ & 17.01 & $8.0 \mathrm{E}-06$ & $2.65 \mathrm{E}-02$ & 150 & 1.24 \\
\hline $808-717$ & $94045.665^{(a)}$ & 21.52 & 8.7E-06 & $3.00 \mathrm{E}-02$ & 150 & 1.43 \\
\hline $331-220$ & $96421.008^{(a),(b)}$ & 8.70 & $1.0 \mathrm{E}-05$ & $1.52 \mathrm{E}-02$ & 150 & 0.73 \\
\hline $18513-18414$ & 97912.135 & 118.10 & $8.4 \mathrm{E}-06$ & $3.04 \mathrm{E}-02$ & 150 & 1.49 \\
\hline $808-707$ & 98662.010 & 21.52 & 4.7E-06 & 1.47E-02 & 150 & 0.72 \\
\hline $827-726$ & 100647.469 & 24.03 & 4.7E-06 & $1.40 \mathrm{E}-02$ & 150 & 0.70 \\
\hline $818-707$ & $102188.761^{(a)}$ & 21.69 & $1.2 \mathrm{E}-06$ & $3.41 \mathrm{E}-02$ & 150 & 1.70 \\
\hline $523-414$ & 103094.044 & 11.39 & $4.9 \mathrm{E}-06$ & $9.71 \mathrm{E}-03$ & 150 & 0.49 \\
\hline $1459-14410$ & 103204.976 & 77.85 & $8.9 \mathrm{E}-06$ & $2.99 \mathrm{E}-02$ & 150 & 1.51 \\
\hline $625-514$ & $105436.485^{(a)}$ & 14.97 & 7.2E-06 & $1.57 \mathrm{E}-02$ & 150 & 0.81 \\
\hline $909-818$ & $107006.105^{(a),(b)}$ & 26.82 & $1.4 \mathrm{E}-05$ & $3.93 \mathrm{E}-02$ & 150 & 2.01 \\
\hline $432-321$ & $108983.168^{(a)}$ & 11.12 & $1.2 \mathrm{E}-05$ & $1.75 \mathrm{E}-02$ & 150 & 0.91 \\
\hline $431-322$ & $109160.580^{(a)}$ & 11.12 & $1.2 \mathrm{E}-05$ & $1.74 \mathrm{E}-02$ & 150 & 0.91 \\
\hline $928-827$ & 113085.512 & 29.46 & $6.8 \mathrm{E}-06$ & $1.73 \mathrm{E}-02$ & 150 & 0.91 \\
\hline $919-808$ & $113153.015^{(a),(b)}$ & 26.95 & 1.7E-06 & $4.26 \mathrm{E}-02$ & 150 & 2.24 \\
\hline $972-871$ & 113828.145 & 54.83 & $2.9 \mathrm{E}-06$ & $6.12 \mathrm{E}-03$ & 150 & 0.32 \\
\hline $946-845$ & 114012.677 & 36.32 & $5.9 \mathrm{E}-06$ & $1.41 \mathrm{E}-02$ & 150 & 0.74 \\
\hline $945-844$ & 114031.614 & 36.32 & $5.9 \mathrm{E}-06$ & $1.41 \mathrm{E}-02$ & 150 & 0.74 \\
\hline $17611-17512$ & 126748.398 & 113.19 & $1.6 \mathrm{E}-05$ & $3.50 \mathrm{E}-02$ & 150 & 1.94 \\
\hline $1046-945$ & 126783.156 & 42.40 & 8.6E-06 & $1.75 \mathrm{E}-02$ & 150 & 0.97 \\
\hline $1468-1459$ & 127852.183 & 83.99 & $1.6 \mathrm{E}-05$ & $3.30 \mathrm{E}-02$ & 150 & 1.83 \\
\hline $15610-15511$ & 127659.038 & 93.11 & $1.6 \mathrm{E}-05$ & $3.41 \mathrm{E}-02$ & 150 & 1.89 \\
\hline $16611-16512$ & 127377.638 & 102.84 & $1.6 \mathrm{E}-05$ & $3.48 \mathrm{E}-02$ & 150 & 1.93 \\
\hline $963-954$ & 128562.724 & 47.53 & $1.2 \mathrm{E}-05$ & $2.10 \mathrm{E}-02$ & 150 & 1.17 \\
\hline $1065-1056$ & 128487.914 & 53.60 & $1.3 \mathrm{E}-05$ & $2.44 \mathrm{E}-02$ & 150 & 1.36 \\
\hline $1367-1358$ & 128075.357 & 75.48 & $1.5 \mathrm{E}-05$ & $3.16 \mathrm{E}-02$ & 150 & 1.75 \\
\hline $1368-1359$ & 128097.570 & 75.48 & $1.5 \mathrm{E}-05$ & $3.16 \mathrm{E}-02$ & 150 & 1.75 \\
\hline $1266-1257$ & 128249.483 & 67.58 & $1.5 \mathrm{E}-05$ & $2.96 \mathrm{E}-02$ & 150 & 1.65 \\
\hline $1019-918$ & 128225.980 & 34.64 & $1.0 \mathrm{E}-05$ & 2.19E-02 & 150 & 1.22 \\
\hline $1267-1258$ & 128259.465 & 67.58 & $1.5 \mathrm{E}-05$ & $2.96 \mathrm{E}-02$ & 150 & 1.65 \\
\hline $1064-1055$ & 128486.347 & 53.60 & $1.3 \mathrm{E}-05$ & $2.44 \mathrm{E}-02$ & 150 & 1.36 \\
\hline $11011-10110$ & 132290.717 & 39.14 & $2.8 \mathrm{E}-05$ & $5.94 \mathrm{E}-02$ & 150 & 3.32 \\
\hline $634-523$ & 133619.742 & 17.81 & $1.7 \mathrm{E}-05$ & $2.26 \mathrm{E}-02$ & 150 & 1.28 \\
\hline $1192-1091$ & 139104.681 & 85.53 & $4.5 \mathrm{E}-06$ & $6.26 \mathrm{E}-03$ & 150 & 0.36 \\
\hline $1193-1092$ & 139104.681 & 85.53 & $4.5 \mathrm{E}-06$ & $6.26 \mathrm{E}-03$ & 150 & 0.36 \\
\hline $1183-1082$ & 139131.647 & 75.99 & $6.4 \mathrm{E}-06$ & $9.50 \mathrm{E}-03$ & 150 & 0.54 \\
\hline $1184-1083$ & 139131.647 & 75.99 & $6.4 \mathrm{E}-06$ & $9.50 \mathrm{E}-03$ & 150 & 0.54 \\
\hline $1166-1065$ & 139230.454 & 60.28 & $9.5 \mathrm{E}-06$ & $1.58 \mathrm{E}-02$ & 150 & 0.91 \\
\hline $1165-1064$ & 139230.502 & 60.28 & $9.5 \mathrm{E}-06$ & $1.58 \mathrm{E}-02$ & 150 & 0.91 \\
\hline $1147-1046$ & 139567.307 & 49.10 & $1.2 \mathrm{E}-05$ & $2.10 \mathrm{E}-02$ & 150 & 1.21 \\
\hline $16710-16611$ & 151281.705 & 110.10 & $2.5 \mathrm{E}-05$ & 3.69E-02 & 150 & 2.16 \\
\hline $1478-1469$ & 151616.943 & 91.27 & $2.4 \mathrm{E}-05$ & $3.45 \mathrm{E}-02$ & 150 & 2.02 \\
\hline $1377-1368$ & 151740.138 & 82.76 & $2.3 \mathrm{E}-05$ & $3.25 \mathrm{E}-02$ & 150 & 1.91 \\
\hline $871-862$ & 152054.582 & 49.36 & $1.2 \mathrm{E}-05$ & $1.36 \mathrm{E}-02$ & 150 & 0.80 \\
\hline $872-863$ & 152054.583 & 49.36 & $1.2 \mathrm{E}-05$ & $1.36 \mathrm{E}-02$ & 150 & 0.80 \\
\hline $1258-1157$ & 152058.401 & 61.42 & $1.5 \mathrm{E}-05$ & $2.20 \mathrm{E}-02$ & 150 & 1.29 \\
\hline $1257-1156$ & 152064.369 & 61.42 & $1.5 \mathrm{E}-05$ & $2.20 \mathrm{E}-02$ & 150 & 1.90 \\
\hline $11210-1019$ & 155300.752 & 42.09 & $.25 \mathrm{E}-04$ & $3.83 \mathrm{E}-02$ & 150 & 2.26 \\
\hline $13113-12012$ & 158512.466 & 53.75 & $.51 \mathrm{E}-04$ & $8.07 \mathrm{E}-02$ & 150 & 4.74 \\
\hline
\end{tabular}

Notes. ${ }^{(a)}$ Attempted in Orion KL by Cunningham et al. (2007). (b) Attempted in Sgr B2 by Cunningham et al. (2007). ALMA Band 3 $=84-116 \mathrm{GHz}$. ALMA Band $4=125-163 \mathrm{GHz}$.

transitions. Interestingly, we identified a few intense transitions of PrO in Band $3(84-116 \mathrm{GHz})$ and Band $4(125-163 \mathrm{GHz})$ which are not blended. In Table 9, we point out all the potentially observable transitions of $\mathrm{PrO}$ in the hot core region. Based on our simple LTE model, we isolated some strong transitions of PrO. We further used the ALMA simulator to check the integration time required to observe these transitions by ALMA. We found that for ALMA Band 4 (for e.g $130 \mathrm{GHz}$ ), with $20 \mathrm{mK}$ RMS noise, $0.4 \mathrm{~km} \mathrm{~s}^{-1}$ spectral resolution, and 43 antennas along with the dual polarization, $1 \mathrm{hr}$ on-source integration time is required for $5 \sigma$ detection of $\mathrm{PrO}$ in $\mathrm{Sgr} \mathrm{B} 2(\mathrm{~N})$ with an angular resolution 


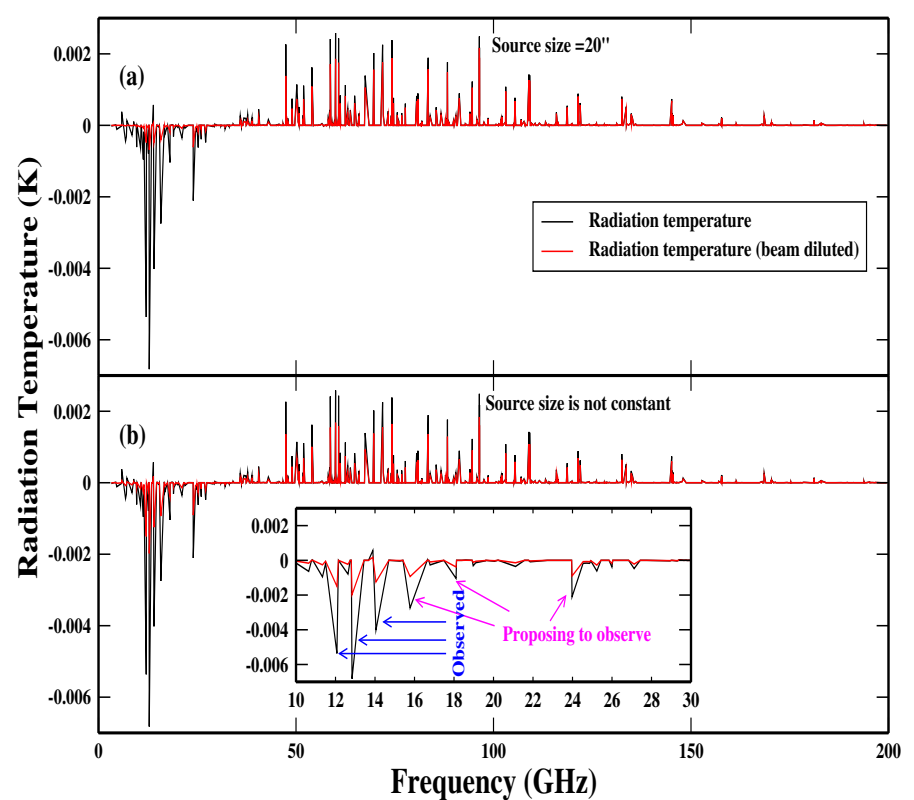

Fig. 7. Line parameters of PrO for non-LTE condition by considering ( $a$ ) constant source size (20") and (b) varied source size (Hollis et al. 2007). The observed and other possible transitions are highlighted inside a separate box in Fig. 7.

of $1.5^{\prime \prime}$. For the similar configuration, $3 \mathrm{~h}$ on-source integration time is required for a Band 3 (e.g., $100 \mathrm{GHz}$ ) observation with ALMA.

\subsubsection{Non-LTE}

In panels $a$ and $b$ of Fig. 7, we show our computed radiation temperature for the various transitions of $\mathrm{PrO}$ within a wide range of frequency $(1-200 \mathrm{GHz})$. In this case, our target was to find out the line parameters that are relevant for the observations performed by McGuire et al. (2016). Thus, we considered, $T_{\mathrm{ex}}=5 \mathrm{~K}$, a column density of $\mathrm{PrO}=1 \times 10^{13} \mathrm{~cm}^{-2}$, a $F W H M=15 \mathrm{Km} \mathrm{s}^{-1}$ (for the observed three transitions, McGuire et al. 2016 obtained a full width at half maximum (FWHM) of 11.6, 15.8, and 19.6, respectively, and we considered the average of these three FWHMs) and $n_{\mathrm{H}_{2}}=10^{5} \mathrm{~cm}^{-3}$. For this non-LTE model, we used GBT $100 \mathrm{~m}$ telescopic parameters. Background continuum temperature measurement was already carried out by Hollis et al. (2007). These authors showed the observed continuum antenna temperatures by the GBT spectrometer toward SgrB2 (N-LMH). We considered this variation of background temperature by digitally extracting Fig. 1 of Hollis et al. (2007) using an online programme ${ }^{4}$. For the GBT $100 \mathrm{~m}$ telescope, the changes in continuum temperature beyond $40 \mathrm{GHz}$ are very small ${ }^{5}$. Extracting the values from Hollis et al. (2007), we have the continuum temperature $\sim 3.35 \mathrm{~K}$ at $49 \mathrm{GHz}$. Beyond this, they did not provide any data for the continuum temperature, so we considered a fixed continuum temperature of about $2.73 \mathrm{~K}$ beyond $100 \mathrm{GHz}$. In between the 49 and $100 \mathrm{GHz}$ we interpolated the continuum temperature from 3.35 to $2.73 \mathrm{~K}$. We considered the variation of beam size by considering the relation $\sim \frac{744}{v}$ (Hollis et al. 2007). In Fig. 7a, we considered that the source size is constant at $20^{\prime \prime}$ and in Fig. $7 \mathrm{~b}$, we considered the source size variation using $\theta_{\mathrm{s}}=\frac{143}{\gamma^{0.52}}$ (Hollis et al. 2007). We present the radiation temperatures of the various

4 https://apps.automeris.io/wpd

5 Fig. 1 of Hollis et al. (2007).

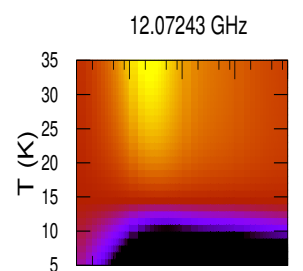

$15.77513 \mathrm{GHz}$

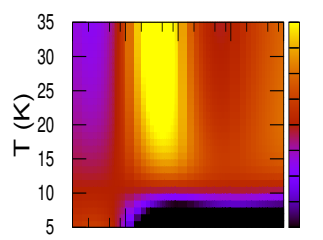

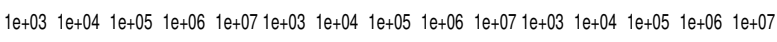

$$
\mathrm{n}_{\mathrm{H} 2}\left(\mathrm{~cm}^{-3}\right) \quad \mathrm{n}_{\mathrm{H} 2}\left(\mathrm{~cm}^{-3}\right) \quad \mathrm{n}_{\mathrm{H} 2}\left(\mathrm{~cm}^{-3}\right)
$$

Fig. 8. Parameter space for the radiation temperature of the most probable 6 transitions with non-LTE condition.

transitions of PrO in Fig. 7a and b, considering the beam dilution effect and avoiding this effect. Most interestingly, with the given conditions, we obtained all the three transitions $(12.07,12.8$, and $14.04 \mathrm{GHz}$ ) in absorptions. Additionally, we identified three more transitions at $15.78 \mathrm{GHz}, 18.1 \mathrm{GHz}$, and $23.98 \mathrm{GHz}$, which might potentially be observed around the same region where the other three transitions were observed.

We further worked on these six transitions to find out the region that shows the absorption feature. In this effort, we used a wide range of parameter spaces (by varying the number density and kinetic temperature of the medium) to find out the probable absorption zone for these transitions. We used the RADEX program again for this purpose. In Fig. 8, we show the variation of the radiation temperature depending on the $\mathrm{H}_{2}$ density $\left(10^{4}-10^{7} \mathrm{~cm}^{-3}\right)$ and kinetic temperature $(5-35 \mathrm{~K})$. This figure depicts that the absorptions are prominent around the low kinetic temperature $(5-10 \mathrm{~K})$ and for $n_{\mathrm{H}_{2}}>10^{4} \mathrm{~cm}^{-3}$. The value of the color box at the end of the panels represents the obtained radiation temperature of the transitions in $\mathrm{K}$.

In addition to the three transition of $\mathrm{PrO}$ discussed above, McGuire et al. (2016) observed 18 transitions of acetone and 11 transitions of propanal from the Prebiotic Interstellar Molecular Survey (PRIMOS). To test the fate of these transitions with the collisional rate file adopted from e- $\mathrm{CH}_{3} \mathrm{OH}$, we calculated the radiation temperature of these transitions for a wide range of parameter spaces. We further explored the validity of our collisional data file by checking the computed radiation temperature of propanal and acetone in PRIMOS. In Figs. A.1 and A.2, we show the radiation temperature of 11 transitions of propanal and 18 transitions of acetone that were observed in PRIMOS. Figure A.1 shows that for the first six transitions of propanal, we obtained the absorption feature at $T_{\text {ex }}=5-7 \mathrm{~K}$ and relatively at higher densities $\left(n_{\mathrm{H}_{2}}>10^{5} \mathrm{~cm}^{-3}\right)$. For the transitions at 29.619 and $31.002 \mathrm{GHz}$, we obtained the absorption features at relatively lower $\mathrm{H}_{2}$ densities $\left(10^{3}-10^{4} \mathrm{~cm}^{-3}\right)$ and kinetic temperatures $(10-35 \mathrm{~K})$. We noticed that the last three transitions of propanal show emission for the whole range of density and temperature adopted in this work. Similarly in case of Fig. A.2, for the first 14 transitions of acetone, we obtained the absorption feature within a minimal zone of parameter space, but for the last four transitions we did not receive the absorption feature. Since then we saw a significant discrepancy between our calculated and observed radiation temperature at the higher frequencies, which 
could be attributed to the unavailability of the collisional rates and its present approximation.

Our non-LTE model accurately reproduces the three observed transitions of $\mathrm{PrO}$ in absorption, and for this, we used observed parameters such as excitation temperature, FWHM, and column density of PrO following McGuire et al. (2016). We also found a good agreement between the observed transitions of propanal and acetone with our calculated non-LTE transitions. The parameter spaces for the radiation temperature of the most probable transitions of PrO, propanal, and acetone are presented (Figs. 8, A.1 and A.2) with the non-LTE condition. Similar results obtained by observation (McGuire et al. 2016) and radiative transfer model are used to constrain the physical conditions (density, temperature) of the region in which these molecules were observed.

In Table 9, we already pointed out the line parameters of various $\mathrm{PrO}$ transitions for the hot core region that lies in the ALMA Band 3 and Band 4 regions. For all the transitions shown in Table 9. we show the variations of radiation temperatures in Fig. A.3 for a wide range of parameter spaces. In constructing the parameter space for the hot core region, we used $T_{\text {ex }}=$ $5-160 \mathrm{~K}$ and $n_{\mathrm{H}_{2}}=10^{4}-10^{7} \mathrm{~cm}^{-3}$. Outside each panel, a color box is placed to show the radiation temperature in K. Figure A.3 gives information that is very useful to gain an understanding of the emission feature of these viable transitions before its real observation.

\subsection{Estimation of physical properties from obtained line parameters}

Mangum \& Wootten (1993) used a formaldehyde $\left(\mathrm{H}_{2} \mathrm{CO}\right)$ molecule to trace kinetic temperature and spatial density within molecular clouds. Normally, symmetric rotor molecules (e.g., $\mathrm{NH}_{3}, \mathrm{CH}_{3} \mathrm{CN}$, and $\mathrm{CH}_{3} \mathrm{C}_{2} \mathrm{H}$ ) are used for the measurements of kinetic temperature. However, the usage of these species are doubtful because of the spatially variable abundances and complex excitation properties. The main reason behind the choice of formaldehyde was that it permeates the ISM at a relatively high abundance. Formaldehyde is a slightly asymmetric rotor molecule that should possess closer kinetic temperature sensitivities such as purely symmetric rotors. Since $\mathrm{PrO}$ is an asymmetric top molecule, the ratio of lines from different $\mathbf{J}$ states would be used as the density tracers and the ratio of lines from the same $\mathrm{J}$ state but different K-states could be used as probes of the regional temperature.

\subsubsection{Kinetic temperature measurements}

In the case of symmetric rotors, $\Delta K_{\mathrm{a}}=0$ dictates the dipole selection rules. Transitions between other $K_{\mathrm{a}}$ values are only possible by the collisional excitation. Owing to this unique feature, a comparison between the energy level populations from different $K_{\mathrm{a}}$ levels within the same symmetry species may be used as a measure of the kinetic temperature. If we consider the ratio between two transitions that could be measured within the same frequency band, various observational uncertainties could be nullified.

Propylene oxide is an asymmetric rotor. We can check the line ratio of propylene oxide for the measurement of temperature and check the consistency of this method with that obtained for $\mathrm{H}_{2} \mathrm{CO}$. Figure 9 depicts the rotational energy level diagram of propylene oxide. Because of its complexity, $\mathrm{PrO}$ is not as widespread as $\mathrm{H}_{2} \mathrm{CO}$. On the other hand, $\mathrm{PrO}$ is also a slightly asymmetric top molecule, and thus we can compare

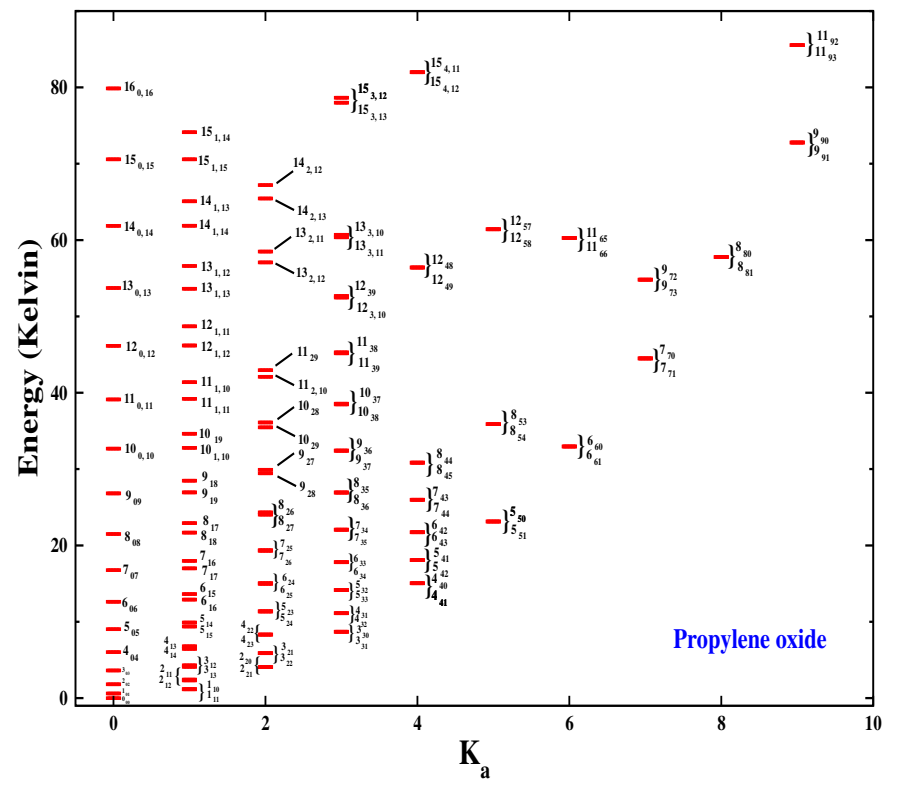

Fig. 9. Rotational energy level diagram of propylene oxide.

the line ratios obtained by the $\mathrm{PrO}$ observation with the $\mathrm{H}_{2} \mathrm{CO}$ observation to derive the precise kinetic temperature of the source. The collisions primarily connect different $K_{\mathrm{a}}$ ladders of PrO. Thus the relative population occupying the ground states of these two $K_{\mathrm{a}}$ ladders are related by the Boltzmann equation at Kinetic temperature. Based on the selection process of Mangum \& Wootten (1993) for the measurement of the kinetic temperature, we used the following selection rule to have the line ratio between two transitions. Suppose the line ratio $(R)$ between the two transitions is

$R=\frac{J 1 K_{\mathrm{a} 1} K_{\mathrm{c} 1}-J 2 K_{\mathrm{a} 2} K_{\mathrm{c} 2}}{J 3 K_{\mathrm{a} 3} K_{\mathrm{c} 3}-J 4 K_{\mathrm{a} 4} K_{\mathrm{c} 4}}$

where, $J_{\mathrm{i}}, K_{\mathrm{a} i}, K_{\mathrm{c} i}(i=1,4)$ are used to denote the quantum numbers of the energy levels involved in the transition. We used the following selection rules for the measurement of the kinetic temperature from the line ratio: (a) $\Delta J=1$ (i.e., $J 1-J 2=J 3-J 4=1$ ), (b) $J 1=J 3$ and $J 2=J 4$, (c) $\Delta K_{\mathrm{a}}=0$ (i.e., $\left.K_{\mathrm{a} 1}-K_{\mathrm{a} 2}=K_{\mathrm{a} 3}-K_{\mathrm{a} 4}=0\right),\left(\right.$ d) $K_{\mathrm{a} 1} \neq K_{\mathrm{a} 3}, K_{\mathrm{a} 1} \neq K_{\mathrm{a} 4}$, $K_{\mathrm{a} 2} \neq K_{\mathrm{a} 3}, K_{\mathrm{a} 2} \neq K_{\mathrm{a} 4}$, (e) $\Delta K_{\mathrm{c}}=1$ (i.e., $K_{\mathrm{c} 1}-K_{\mathrm{c} 2}=K_{\mathrm{c} 3}=$ $K_{\mathrm{c} 4}=1$ ), and (f) the frequency should be closely spaced. Unfortunately, the observed three transitions (McGuire et al. 2016) did not fulfill the above criterion. Thus, we are unable to predict the kinetic temperature from the line ratio method in this work. Alternatively, we focused on the transitions of PrO that might be observed in the hot core region and identified some of the transitions that might be useful to find out the physical properties of the perceived source. In Table 9, we already selected some transitions based on the obtained intensity and avoided blending with possible interstellar species. Among these, we found out some transitions for the measurement of the kinetic temperature. The advantage of plotting these line ratios are that these are less sensitive to the calibration errors and both the lines would have been equally affected. It is worthy to calculate several transition ratios to avoid the discrepancy in measuring the kinetic temperature. We found out following line pairs for the measurement of the kinetic temperature: $7_{35}-6_{34} / 7_{44}-6_{43}\left(E_{7_{44}}=\right.$ $25.98 \mathrm{~K}), 7_{35}-6_{34} / 7_{43}-6_{42}\left(E_{7_{43}}=25.98 \mathrm{~K}\right), 8_{27}-7_{26} / 8_{54}-$ $7_{53}\left(E_{8_{54}}=35.89 \mathrm{~K}\right), 9_{28}-8_{27} / 9_{72}-8_{71}\left(E_{9_{72}}=54.83 \mathrm{~K}\right)$, $9_{45}-8_{44} / 9_{46}-8_{45}\left(E_{9_{46}}=36.32 \mathrm{~K}\right), 10_{19}-9_{18} / 10_{46}-9_{45}\left(E_{10_{46}}=\right.$ 


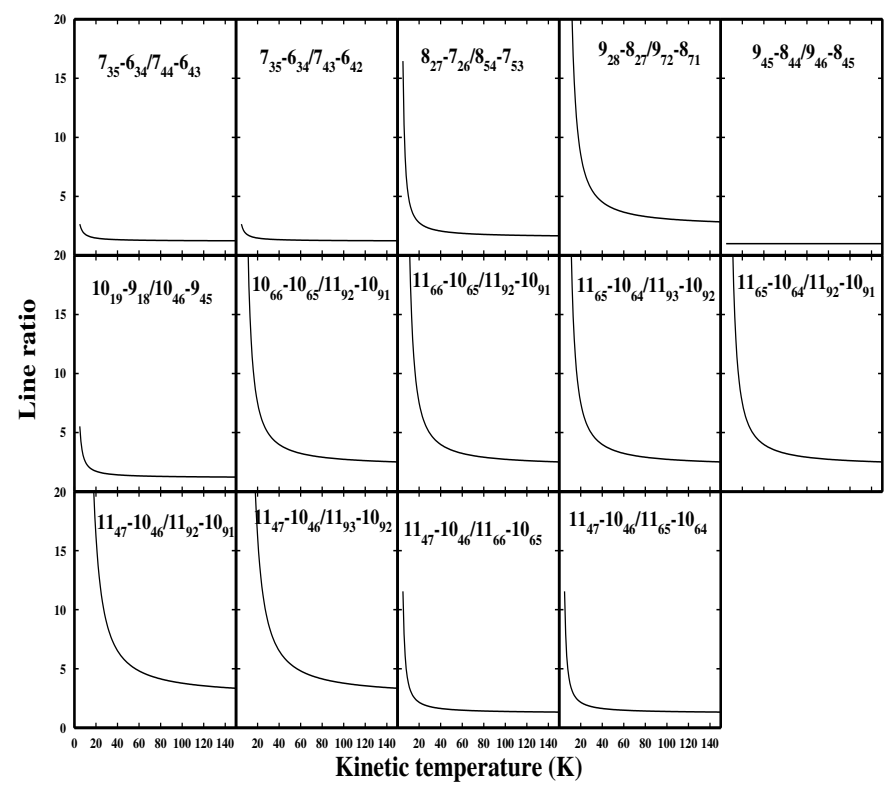

Fig. 10. Variation of line ratio with the kinetic temperature in LTE approximation.

$42.40 \mathrm{~K}), 10_{66}-10_{65} / 11_{92}-10_{91}\left(E_{11_{92}}=85.53 \mathrm{~K}\right), 11_{66}-$ $10_{65} / 11_{92}-10_{91}\left(E_{11_{92}}=85.53 \mathrm{~K}\right), 11_{65}-10_{64} / 11_{93}-10_{92}$ $\left(E_{11_{93}}=85.53 \mathrm{~K}\right), 11_{65}-10_{64} / 11_{92}-10_{91}\left(E_{11_{92}}=\right.$ $85.53 \mathrm{~K}), 11_{47}-10_{46} / 11_{92}-10_{91}\left(E_{11_{93}}=85.53 \mathrm{~K}\right), 11_{47}-10_{46} /$ $11_{93}-10_{92}\left(E_{11_{93}}=85.53 \mathrm{~K}\right), 11_{47}-10_{46} / 11_{66}-10_{65}\left(E_{11_{66}}=\right.$ $60.28 \mathrm{~K}), 11_{47}-10_{46} / 11_{65}-10_{64}\left(E_{11_{65}}=60.28 \mathrm{~K}\right)$. The line ratios of $\mathrm{PrO}$ mentioned in this work have the transitions from various $K_{\mathrm{a}}$ ladders (i.e., with the $\left.K_{\mathrm{a}}=3,4,5,6,7,8,9\right)$. It is obvious that around the low-temperature region, the ground state of the $K_{\mathrm{a}}$ ladders are well populated and lower $K_{\mathrm{a}}$ values would pile up earlier than those of the higher $K_{\mathrm{a}}$ values.

From Fig. 9, the ground state of $K_{\mathrm{a}}=3,4,5,6,7,8$, and 9 ladder is $3_{31}, 4_{41}, 5_{51}, 6_{61}, 7_{71}, 8_{81}$, and $9_{91}$, respectively. The upstate energy of the each transitions considered are all below $100 \mathrm{~K}$. Let us first check under LTE approximation how these ratios can behave. At the high densities, LTE conditions are best suited. Therefore, the relative population occupying the ground states from the two $K_{\mathrm{a}}$ ladders should obey the Boltzmann equation at the kinetic temperature. Mangum \& Wootten (1993) derived the following relation for the estimation of kinetic temperature from the obtained line ratio if both the transitions are optically thin:

$T_{\mathrm{K}}=\left[E\left(J, K^{\prime}\right)-E(J, K)\right]\left[\ln \left(\frac{S_{J K^{\prime}} \int J\left(T_{\mathrm{R}}(J, K) \mathrm{d} v\right.}{S_{J K} \int J\left(T_{\mathrm{R}}\left(J, K^{\prime}\right) \mathrm{d} v\right.}\right)\right]^{-1}$,

where, $E\left(J, K^{\prime}\right)$ is the upstate energy of the bottom transition, $E(J, K)$ is the upstate energy of the transition at the numerator, $S_{J K^{\prime}}$ and $S_{J K}$ are the transition line strengths of the two upstate involved in the transition ratio, and $T_{\mathrm{R}}\left(J, K^{\prime}\right), T_{\mathrm{R}}(J, K)$ are the obtained radiation temperatures. By using the above relation and using the line strengths available ${ }^{6}$, we computed the line ratio of the radiation temperature for the above transitions. Figure 10 shows the variation of these line ratios with the various kinetic temperatures. It is interesting to note that around the low temperature, this ratio is maximum and drastically reduced with increasing temperature. After a certain temperature, it remains roughly invariant (small decreasing slope) on the

6 https://www.cv.nrao.edu/php/splat/advanced.php increase of the kinetic temperature. This feature would be better understood if we explain it in terms of the 1st transition ratio, $7_{35}-6_{34} / 7_{44}-6_{43}\left(E_{7_{44}}=25.98 \mathrm{~K}\right)$ (see first panel of Fig. A.4). Around the low temperature $\left(T_{\mathrm{K}}<25.98 \mathrm{~K}\right)$ the ground state of the $K_{\mathrm{a}}=3$ (i.e., $3_{31}$ ) and $K_{\mathrm{a}}=4$ ladder (i.e., $4_{41}$ ) are mostly populated. Since $6_{34}$ level lies below the $6_{43}$ level, its population is comparatively higher at the low temperature. Similarly, $7_{35}$ level lies below the $7_{44}$ level and this implies that the population is higher in $7_{35}$ level. As we increase the temperature, the population at the ground state falls much faster. Since the upper and lower levels of the transition at the denominator are at a relatively higher energy levels than those of the upper and lower energy levels of the transition at the top, the population in the $6_{43}$ level falls much faster than the $7_{44}$ level and shows a faster increasing trend of $7_{44}-6_{43}$ transition in comparison to the top transition. At $T_{\mathrm{K}}>E_{\mathrm{u}}$ the decreasing slope of the ratio changes and at $T_{\mathrm{K}} \gg E_{\mathrm{u}}$ it tends to become roughly invariant on the kinetic temperature. The expression provided in Eq. (3) is independent of the number density of the cloud and thus provides the kinetic temperature at the LTE condition. Since we considered the hot core region, where the $\mathrm{H}_{2}$ density should be on the higher side (may vary in between $\sim 10^{5}$ and $10^{7} \mathrm{~cm}^{-3}$ ) and temperatures should be between 100-200 K, the LTE condition is best suited. Since from various observations, we know the kinetic temperature of Sgr B2 (Bonfand et al. 2017), we may constrain the line ratio of $\mathrm{PrO}$ around this region. Our obtained line ratios from the LTE condition are presented in Table 10 at $T_{\mathrm{K}}=150 \mathrm{~K}$.

Since we already prepared our approximated collisional rate file, we again calculated these line ratios with the non-LTE calculation for a wide range of parameter spaces. In our calculations, we varied the kinetic temperature from 5 to $160 \mathrm{~K}$ and kept the column density of PrO constant at $10^{13} \mathrm{~cm}^{-2}$. We also considered the column density as high as $1.74 \times 10^{16} \mathrm{~cm}^{-2}$, which we obtained from our two-phase model presented in Fig. 4 and assuming a $H_{2}$ column density of $10^{24} \mathrm{~cm}^{-2}$; in considering the column density, we see the effect on the calculated ratio but do not find any drastic difference. In Fig. A.4, we show the line ratios that might be useful to trace precisely the temperature of the region where these lines would be observed. At the top of the panel, we mentioned the upstate energy of four energy states that were involved in the transition ratio. In Table 10, we also note our line ratios obtained from the non-LTE calculations with $n_{\mathrm{H}}=10^{7} \mathrm{~cm}^{-3}$ and $T_{\text {ex }}=150 \mathrm{~K}$. It should be noted that the line ratios obtained from the LTE calculation are uncertain by $<30 \%$ (Mangum \& Wootten 1993) and we adopt random approximation for the consideration of our collisional data file. Despite this fact we obtained excellent agreement between the LTE consideration and non-LTE calculation (Table 10).

\subsubsection{Spatial density measurements}

Measurement of the spatial density is more critical than the measurement of the kinetic temperature. Based on the study by Mangum \& Wootten (1993), spatial density could be measured by measuring a specific line ratio. Mangum \& Wootten (1993) used the line ratio of various $\mathrm{H}_{2} \mathrm{CO}$ transitions for the measurement of the spatial density. We applied a similar technique to find out the line ratio for some of the observable transitions of $\mathrm{PrO}$ in the hot core region such as $\mathrm{Sgr} \mathrm{B} 2(\mathrm{LMH})$. We used the following criterion for the selection of the transition ratios: (a) $\Delta J=1$ (i.e., $J 1-J 2=J 3-J 4=1$ ), (b) $J 1 \neq J 3$ and $J 2 \neq J 4$, (c) $\Delta K_{\mathrm{a}}=0$ (i.e., $K_{\mathrm{a} 1}-K_{\mathrm{a} 2}=K_{\mathrm{a} 3}-K_{\mathrm{a} 4}=0$ ), (d) $K_{\mathrm{a} 1}=K_{\mathrm{a} 2}=K_{\mathrm{a} 3}=K_{\mathrm{a} 4}$, (e) $\Delta K_{\mathrm{c}}=1$ (i.e., $K_{\mathrm{c} 1}-K_{\mathrm{c} 2}=K_{\mathrm{c} 3}=$ $K_{\mathrm{c} 4}=1$ ), and (f) the frequency should be closely spaced. The 
Table 10. Estimated line ratio of PrO for the measurement of Kinetic temperature at $150 \mathrm{~K}$ from LTE and non-LTE.

\begin{tabular}{ccc}
\hline \hline Line ratio (upstate energy in K) & LTE results & non-LTE results \\
\hline $7_{35}-6_{34} / 7_{44}-6_{43}\left(E_{7_{44}}=25.98\right)$ & 1.24 & 1.25 \\
$7_{35}-6_{34} / 7_{43}-6_{42}\left(E_{7_{43}}=25.98\right)$ & 1.24 & 1.25 \\
$8_{27}-7_{26} / 8_{54}-7_{53}\left(E_{8_{54}}=35.89\right)$ & 1.66 & 1.65 \\
$9_{28}-8_{27} / 9_{72}-8_{71}\left(E_{9_{72}}=54.83\right)$ & 2.84 & 2.78 \\
$9_{45}-8_{44} / 9_{46}-8_{45}\left(E_{9_{46}}=36.32\right)$ & 0.99 & 1.00 \\
$10_{19}-9_{18} / 10_{46}-9_{45}\left(E_{10_{46}}=42.40\right)$ & 1.23 & 1.25 \\
$10_{66}-10_{65} / 11_{92}-10_{91}\left(E_{11_{92}}=85.53\right)$ & 2.51 & 2.53 \\
$11_{66}-10_{65} / 11_{92}-10_{91}\left(E_{11_{92}}=85.53\right)$ & 2.51 & 2.53 \\
$11_{65}-10_{64} / 11_{93}-10_{92}\left(E_{11_{93}}=85.53\right)$ & 2.51 & 2.53 \\
$11_{65}-10_{64} / 11_{92}-10_{91}\left(E_{11_{92}}=85.53\right)$ & 2.51 & 2.53 \\
$11_{47}-10_{46} / 11_{92}-10_{91}\left(E_{11_{93}}=85.53\right)$ & 3.35 & 3.32 \\
$11_{47}-10_{46} / 11_{93}-10_{92}\left(E_{11_{93}}=85.53\right)$ & 3.35 & 3.32 \\
$11_{47}-10_{46} / 11_{66}-10_{65}\left(E_{11_{66}}=60.28\right)$ & 1.33 & 1.31 \\
$11_{47}-10_{46} / 11_{65}-10_{64}\left(E_{11_{65}}=60.28\right)$ & 1.33 & 1.31 \\
\hline
\end{tabular}

above criteria are very rarely satisfied and sometimes the frequency lies very far away, and thus absolute calibration of each transition is required. The observed three transitions (McGuire et al. 2016) do not satisfy the above criterion. We also did not find any other transitions that can satisfy the above criterion around the region (dark cloud condition), where these three transitions were observed. Thus, we selected some more transitions $\left(7_{44}-6_{43} / 9_{46}-8_{45}, 7_{44}-6_{43} / 9_{45}-8_{44}, 7_{44}-6_{42} / 9_{46}-8_{45}, 7_{43}-\right.$ $\left.6_{42} / 9_{45}-8_{44}, 8_{27}-7_{26} / 9_{28}-8_{27}\right)$ from the LTE model of the hot core region (Table 9), which can fulfill the above criterion and are suitable for observation in the hot core region. To constrain a limit on the number density, in Fig. A.5, we show the line ratios of the PrO transitions for $T_{\mathrm{ex}}=150 \mathrm{~K}$. The parameter space is based on the column density of $\mathrm{PrO}$ and the $\mathrm{H}_{2}$ number density of the medium. The column densities are varied between $10^{13}$ and $10^{16} \mathrm{~cm}^{-2}$ and the $\mathrm{H}_{2}$ number density of the medium is varied between $10^{4}$ and $10^{7} \mathrm{~cm}^{-3}$. The density and temperature of the Sgr B2 (LMH) region were well studied, and it would be assumed that the $\mathrm{H}_{2}$ density may vary between $10^{6}$ and $10^{7} \mathrm{~cm}^{-3}$ and the kinetic temperature may vary between 100 and $150 \mathrm{~K}$. Assuming the predicted upper limit of the PrO column density of $6.7 \times 10^{14} \mathrm{~cm}^{-2}$ from Cunningham et al. (2007), we have the line ratio of $0.55,0.57,0.57,0.59$ and 0.8 for the above five transitions in the Sgr B2(LMH), respectively.

\section{Conclusions}

The presence of chiral species in the ISM been recently confirmed by McGuire et al. (2016). The observation of more chiral species and identification of their chirality may provide some insight into the homochirality of various pre-biotic species. In this paper, we studied the chemical evolution of $\mathrm{PrO}$ under various physical conditions and find out the line parameters of its transitions that are relevant to constrain the physical properties of the source. The major conclusions are the following:

- A complete reaction network for the formation of $\mathrm{PrO}$ was prepared. This pathway is implemented in our gas-grain chemical model to find out its chemical evolution. To understand the formation of PrO in the cold environment as observed by (McGuire et al. 2016), we considered a static cloud model; for the formation of $\mathrm{PrO}$ in the hot core region, we considered a two-phase model, i.e., a static isothermal phase followed by a warm-up phase. We found that the reaction between $\mathrm{C}_{3} \mathrm{H}_{6}$ and $\mathrm{O}\left({ }^{3} \mathrm{P}\right)$ with an activation barrier of $40 \mathrm{~K}$ is the dominant means for the formation of $\mathrm{PrO}$ in the ice phase. This ice phase PrO desorbed to the gas phase by various means that could be observed by their rotational transitions. We also considered the formation of $\mathrm{PrO}$ by $\mathrm{O}\left({ }^{1} \mathrm{D}\right)$ but we noticed that we have significant production of PrO instead of this consideration. This is because of the lower activation barrier for the reaction between $\mathrm{C}_{3} \mathrm{H}_{6}$ and $\mathrm{O}\left({ }^{3} \mathrm{P}\right)$.

- We computed various vibrational transitions of $\mathrm{PrO}$ along with its protonated form that might be observable with the forthcoming JWST facility.

- To constrain the physical properties of the cloud, we carried out non-LTE modeling (by considering approximated collisional data file) for the most probable transitions identified by the LTE calculations by considering a wide range of parameter spaces (spanned by the $\mathrm{H}_{2}$ density range of $\sim 10^{3}-10^{7} \mathrm{~cm}^{-3}$ of the collisional partner and the kinetic temperature temperature range of $\sim 5-35 \mathrm{~K})$. We found that the observed three transitions at $12.07243 \mathrm{GHz}\left(1_{10}-1_{01}\right), 12.83734 \mathrm{GHz}\left(2_{11}-2_{02}\right)$, and $14.04776 \mathrm{GHz}\left(3_{12}-3_{03}\right)$ showed absorption features around the high $\mathrm{H}_{2}$ density $\left(10^{4}-10^{7} \mathrm{~cm}^{-3}\right)$ and low temperature $(<10 \mathrm{~K})$ region. Additionally, we found three more transitions (at 15.78, 18.10 , and $23.975 \mathrm{GHz}$ ) that might be observed in absorption around the same region in which the three transitions were identified by McGuire et al. (2016).

- We identified the line parameters suitable for the hot core observation of PrO. We point out potentially observable transitions lying in the ALMA Band 3 and Band 4, which would be used for the for future observations.

- Various line ratios were directly found to be linked with the kinetic temperature and spatial density distribution. Thus from observation, we can extract the physical properties of the star-forming region by comparing their observation with our proposed parameters.

Our result depends on a very simple-minded cloud model that has no rotation; also the evolution was carried out until an estimated time. Thus the estimation of the parameters mentioned above could slightly depend on the evolution time inside the cloud. These aspects will be further explored in the future.

Acknowledgements. This research was possible in part due to a Grant-In-Aid from the Higher Education Department of the Government of West Bengal. A.D. is grateful to ISRO Respond project (Grant No. ISRO/RES/2/402/16-17). P.G. acknowledges the CSIR extended SRF fellowship (Grant No. 09/904 (0013) 2018 EMR-I). We want to acknowledge the reviewer for the numerous suggestions that improved the paper.

\section{References}

Abplanalp, M. J., Förstel, M., \& Kaiser, R. I. 2016, Chem. Phys. Lett., 644, 79 Adams, F. C., Lada, C. J., \& Shu, F. H. 1987, ApJ, 312, 788 Agúndez, M., \& Wakelam, V. 2013, Chem. Rev., 113, 8710 Atkinson, R., \& Cvetanov, R. J. 1972, J. Chem. Phys., 56, 432 Atkinson, R., \& Pitts, J. N. 1974, Chem. Phys. Lett., 27, 467

Bailey, J., Chrysostomou, A., Hough, J. H. 1998, Science, 281, 672 Bacmann, A., Taquet, V., Faure, A., Kahane, C., \& Ceccarelli, C. 2012, A\&A, 541, L12

Becke, A. D. 1988, Phys. Rev. A, 38, 3098

Bergner, J. B., Öberg, K. I., \& Rajappan, M. 2017, ApJ, 845, 29

Bergantini, A., Abplanalp, M. J., Pokhilko, P., et al. 2018, ApJ, 860, 108

Breslow, R., \& Cheng, Z.-L. 2009, Proc. Natl. Acad. Sci., 106, 9144

Breslow, R., Levine, M., \& Cheng, Z. L. 2010, Orig. Life Evol. Biosph., 40, 11

Busemann, H., Young, A. F., Alexander, C. M. O.'D., et al. 2006, Science, 312, 727

Bonfand, M., Belloche, A., Menten, K. M., Garrod, R. T., \& Müller, H. S. P. 2017, A\&A, 604, A60

Cohen, J. 1995, Science, 267, 1265

Creswell, R. A., \& Schwendeman, R. H. 1977, J. Mol. Spectr., 64, 295

Cunningham, M. R., Jones, P. A., Godfrey. P. D., et al. 2007, MNRAS, 376, 1201 
Chakrabarti, S., \& Chakrabarti, S. K. 2000a, A\&A, 354, L6

Chakrabarti, S. K., \& Chakrabarti, S. 2000b, Int. J. Pharm., 74B, 97

Chakrabarti, S. K., Das, A., Acharyya, K., \& Chakrabarti, S. 2006a, A\&A, 457, 167

Chakrabarti, S. K., Das, A., Acharyya, K., \& Chakrabarti, S. 2006b, Bull. Astron. Soc. India, 34, 299

Chakrabarti, S. K., Majumdar, L., Das, A., \& Chakrabarti, S. 2015, Ap\&SS, 357, 90

Chyba, C. F., Thomas, P. J., Brookshaw, L., \& Sagan, K. 1990, Science, 249, 366

Das, A., \& Chakrabarti, S. K. 2011, MNRAS, 418, 545

Das, A., Chakrabarti, S. K., Acharyya, K., \& Chakrabarti, S. 2008a, New Astron., 13,457

Das, A., Acharyya, K., Chakrabarti, S., \& Chakrabarti, S. K. 2008b, A\&A, 486, 209

Das, A., Acharyya, K., \& Chakrabarti, S. K. 2010, MNRAS 409, 789

Das, A., Majumdar, L., Chakrabarti, S. K., \& Chakrabarti, S. 2013a, New Astron., 23, 118

Das, A., Majumdar, L., Chakrabarti, S. K., Saha, R., \& Chakrabarti, S. 2013b, MNRAS, 433, 3152

Das, A., Majumdar, L., Chakrabarti, S. K., \& Sahu, D. 2015a, NewA, 35, 53

Das, A., Majumdar, L., Sahu, D., et al. 2015b, ApJ, 808, 21

Das, A., Sahu, D., Majumdar, L., \& Chakrabarti, S. K. 2016, MNRAS, 455, 540

Das, A., Sil, M., Gorai, P., Chakrabarti, S. K., \& Loison, J. C. 2018, ApJS, 237, 9

DeBoer, G. D., \& Dodd, J. A. 2007, J. Phys. Chem. A, 111, 12977

Dubnikova, F., \& Lifshitz, A. 2000, J. Phys. Chem., 104, 4489

Dickens, J. E., Irvine, W. M., Ohishi, M., et al. 1997, ApJ, 489, 753

Engel, M. H., \& Nagy, B. 1982, Nature, 296, 837

Engel, M. H., \& Macko, S. A. 1997, Nature, 389, 265

Frisch, M. J., Trucks, G. W., Schlegel, H. B., et al. 2015, Gaussian 09, Revision A.02 (Wallingford, CT: Gaussian Inc.)

Garrod, R. T. 2013, ApJ, 765, 60

Garrod, R. T., \& Herbst, E. 2006, A\&A, 457, 927

Garrod, R. T., Wakelam, V., \& Herbst, E. 2007, A\&A, 467, 1103

Gontrani, L., Nunziante, C. S., Stranges, S., Bencivenni, L., \& Pierett, A. 2014, Spectrochim. Acta, 120, 558

Gorai, P., Das, A., Das, A., et al. 2017a, ApJ, 836, 70

Gorai, P., Das, A., Majumdar, L., et al. 2017b, Mol. Astrophys., 6, 36

Gredel, R., Lepp, S., Dalgarno, A., \& Herbst, E. 1989, ApJ, 347, 289

Gupta, V. R., Tandon, P., Rawat, P., Singh, R. N., \& Singh, A. 2011, A\&A, 528, A129

Hartogh, P., Lis, D. C., Bockelée-Morvan, D, et al. 2011, Nature, 478, 218

Hasegawa, T., Herbst, E., \& Leung, C. M. 1992, ApJ, 82, 167

He, J., Shi, J., Hopkins, T., Vidali, G., \& Kaufman, M. J. 2015, ApJ, 801, 120

Herbst, E. 2006, in Springer Handbook of Atomic, Molecular, and Optical Physics, ed. G. W. F. Drake (New York: Springer), 56

Herbst, E., \& Klemperer, W. 1973, ApJ, 185, 505

Herbst, E., \& van Dishoeck, E. F. 2009, ARA\&A, 47, 427

Herbs, E., Roueff, E., \& Talbi, D. 2010, Mol. Phys., 108, 2171

Hershbach, D. R., \& Swalen, J. D. 1958, J. Chem. Phys., 29, 4

Hickson, K. M., Wakelam, V., \& Loison, J.-C. 2016, Mol. Astrophys., 3, 1

Hincelin, U., Wakelam, V., Hersant, F., Guilloteau, S., Loison, J.-C., et al. 2011, A\&A, 530, A61

Hocuk, S., Szúcs, L., \& Caselli, P. 2017, A\&A, 604, A58

Hogerheijde, M. R., van der Tak, F. F. S. 2000, A\&A, 362, 697
Hollis, J. M., Jewell, P. R., Remijan, A. J., \& Lovas, F. J. 2007, ApJ, 660, L126 Holtom, P. D., Bennett, C. J., Osamura, Y., Mason, N. J., \& Kaiser, R. I. 2005, ApJ, 626, 940

Hudosn, R. L., Loeffler, M. J., \& Yocum, K. M. 2017, ApJ, 835, 225

Hunt-Cunningham, M. R., \& Jones, P. A. 2004, IAU Symp., 213, 159

Hunter, E. P., \& Lias, S. G. 1998, J. Phys. Chem. Ref. Data, 27, 413

Knyazev, V. D., Arutyunov, V. S., \& Vedeneev, V. I. 1992, Int. J. Chem. Kinet., 24,545

Lauck, T., Karssemeijer, L., Shulenberger, K., et al. 2015, ApJ, 801, 118

Leonori, F., Balucani, N., Nevrly, V. 2015, J. Phys. Chem. C, 119, 26, 14632

Lee, H. H., Herbst, E., Pineau des Forets, G., Roueff, E., \& Le Bourlot, J. 1996, A\&A, 311, 690

Lee, C., Yang, W., \& Parr, R. G. 1988, Phys. Rev. B, 58, 785

Lin, Z., Talbi, D., Roueff, E., Eric Herbst, E., et al. 2013, ApJ, 765, 80

Lowe, M. A., Alper, J. S., Kawiecki, R., \& Stephens, P. J. 1986, J. Phys. Chem. $90,41,50$

Majumdar, L., Das, A., Chakrabarti, S. K., \& Chakrabarti, S. 2012, Res. Astron. Astrophys., 12, 1613

Majumdar, L., Das, A., Chakrabarti, S. K., \& Chakrabarti, S. 2013, New Astron., 20, 15

Majumdar, L., Das, A., \& Chakrabarti, S. K. 2014a, A\&A, 562, A56

Majumdar, L., Das, A., \& Chakrabarti, S. K. 2014b, ApJ, 782, 73

Mangum, J. G., \& Wootten, A. 1993, ApJS, 89, 123

Marcelino, N., Cernicharo, J., Aguńdez, M., et al. 2007, ApJ, 665, L127

McElroy, D., Walsh, C., Markwick, A. J. 2013, A\&A, 550, A36

McGuire, B. A., Carroll, P. B., Loomis, R. A., et al. 2016, Science, 352, 1449

Nuevo, M., Materese, C. K., \& Sandford, S. A. 2014, ApJ, 793, 125

Öberg, K. I., Garrod, R. T., van Dishoeck, E. F., \& Linnartz, H. 2009, A\&A, 504, 891

Occhiogrosso, A., Viti, S., Ward, M. D., \& Price, S. D. 2012, MNRAS, 427, 2450

Polavarapu, P. L., Hess, Jr. B. A., \& Schaad, L. J. 1985, J. Chem. Phys., 82, 1705

Puzzarini, C., Ali, A., Biczysko, M., \& Barone, V. 2014, ApJ, 792, 118

Rabli, D., \& Flower, D. R. 2010, MNRAS, 406, 95

Raymond, S. N., Quinn, T. R., \& Lunine, J. I. 2004, Icarus, 168, 1

Ruaud, M., Wakelam, V., \& Hersant, F. 2016, MNRAS, 459, 3756

Schiwietz, G., \& Grande, P. L. 2011, Phys. Rev. A, 84, 052703

Schöier, F. L., van der Tak, F. F. S., van Dishoeck, E. F., \& Black, J. H. 2005 A\&A, 432, 369

Sil, M., Gorai, P., Das, A., et al. 2017, ApJ, 853, 2

Shu, F. 1977, ApJ, 214, 488

Stuhl, F., \& Niki, H. 1971, J. Chem. Phys., 55, 3954

Swalen, J. D., \& Hershbach, D. R. 1957, J. Chem. Phys, 27, 100

Su, T., \& Chesnavich, W. J. 1982, J. Chem. Phys., 76, 5183

Vasyunin, A. I., \& Herbst, E. 2013, ApJ, 769, 34

Van der Tak, F. F. S. 2011, Proceedings IAU Symposium No. 280, eds. Cernicharo, J. \& Bachiller, R. (Cambridge: Cambridge University Press)

Van der Tak, F. F. S., Black, J. H., Schöier, F. L., Jansen, D. J., \& van Dishoeck, E. F. 2007, A\&A, 468, 627

Wakelam, V., Smith, I. W. M., Herbst, E., et al. 2010, Space Sci. Rev., 156, 13

Ward, M. D., \& Price, S. P. 2011, ApJ, 741, 2011

Woodall, J., Agndez, M., Markwick-Kemper, A. J., \& Millar, T. J. 2007, A\&A 466, 1197

Woon, D. E. 2002, ApJ, 571, L177

Woon, D. E., \& Herbst, E. 2009, ApJS, 185, 273 


\section{Appendix A: Additional figures}

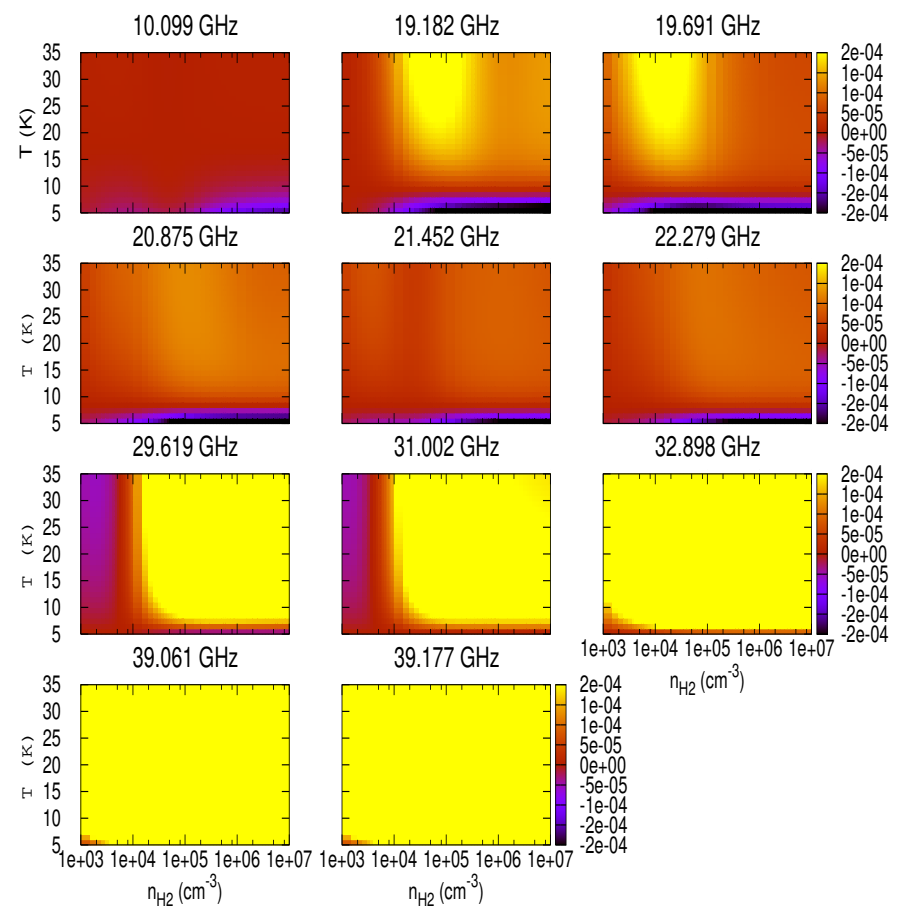

Fig. A.1. Parameter space for the radiation temperature of the 11 observed propanal transitions with non-LTE conditions.

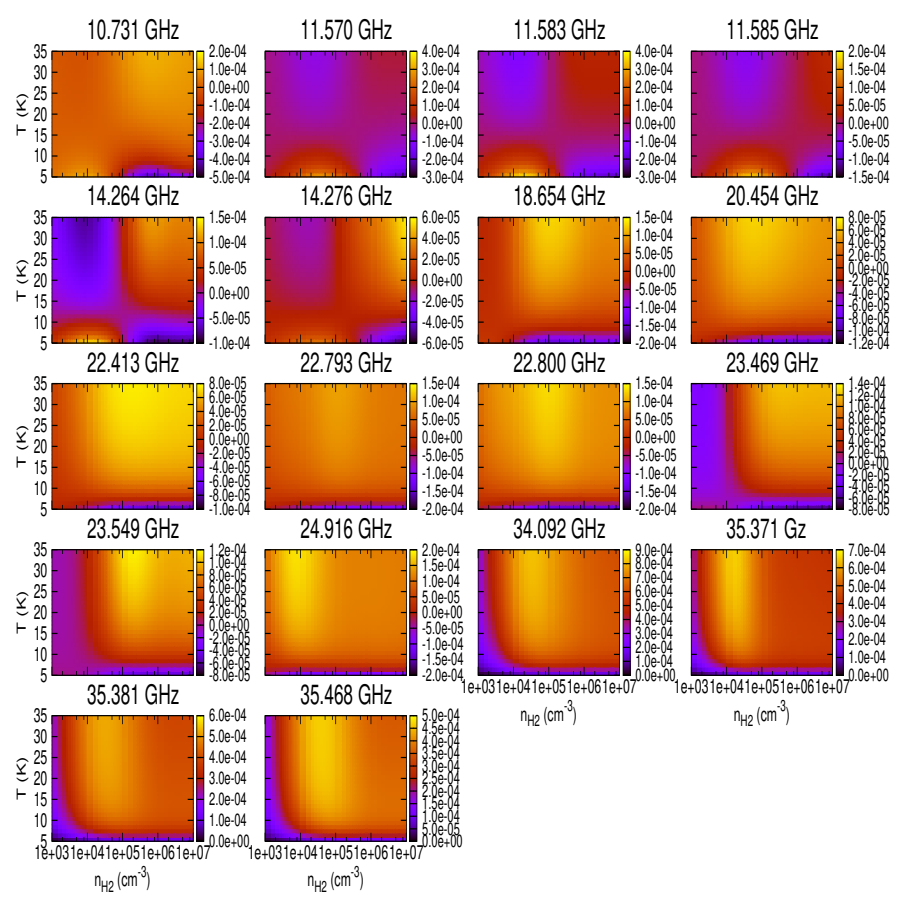

Fig. A.2. Parameter space for the radiation temperature of the 18 observed acetone transitions with non-LTE conditions.
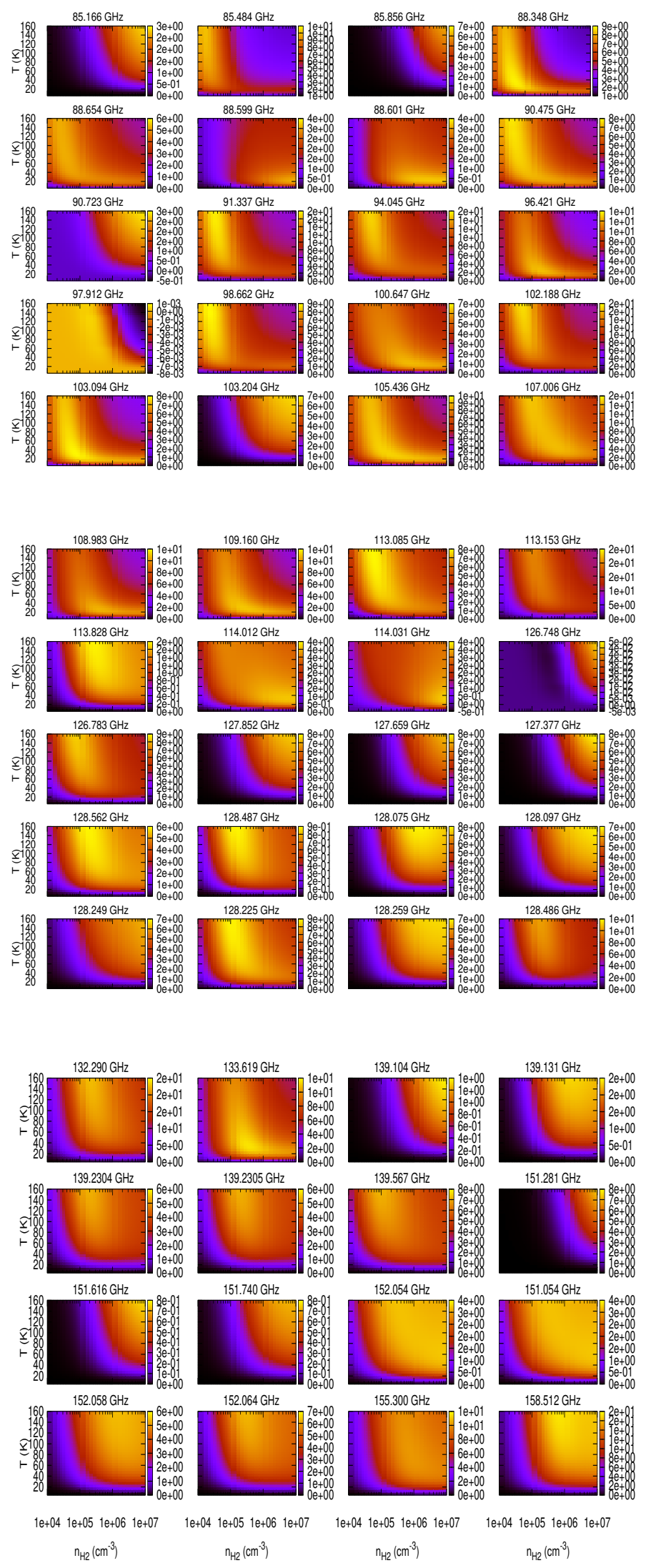

Fig. A.3. Parameter space of the radiation temperature for the probable $\mathrm{PrO}$ transitions in the hot core region. 
A. Das et al.: Modeling of propylene oxide

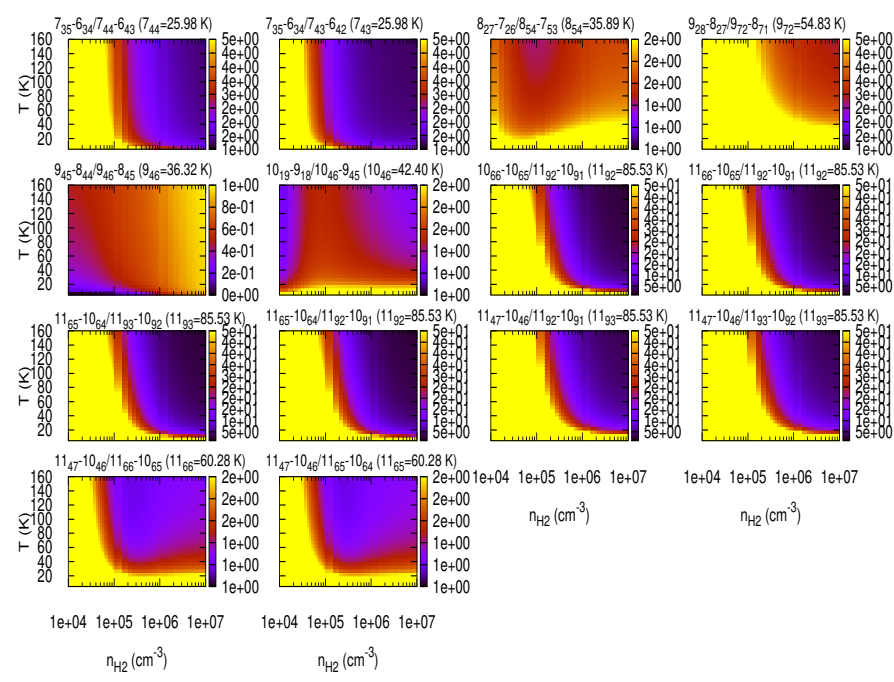

Fig. A.4. Variation of the line ratios (useful for the kinetic temperature measurement) for a wide range of parameter spaces (number density and kinetic temperature).

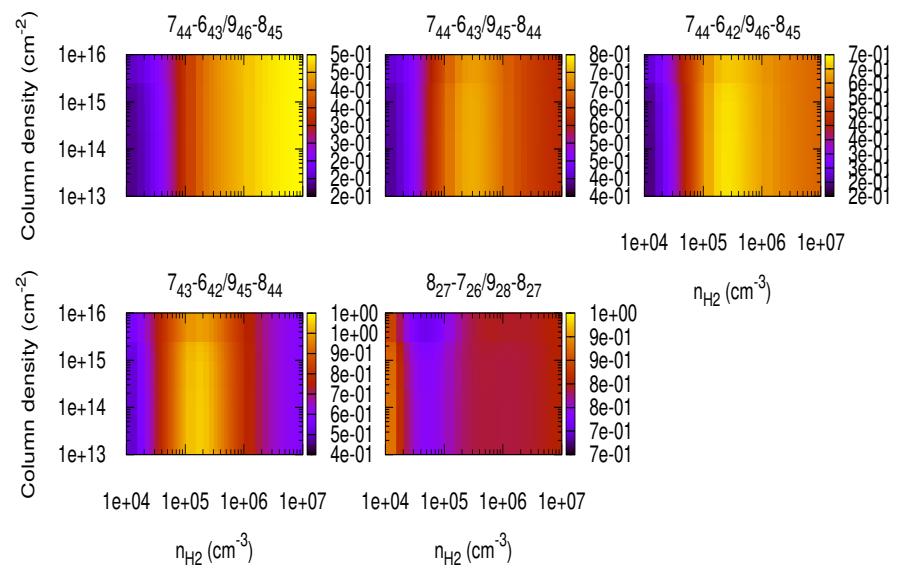

Fig. A.5. Variation of line ratios (useful for the measurement of the spatial density) for a wide range of parameter spaces (column density and number density). 